\title{
1 Salt-marsh areas as copper complexing ligand sources to estuarine and coastal systems
}

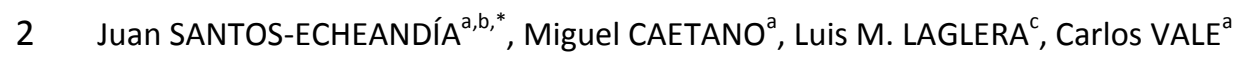

3 a IPMA, Portuguese Institute of Sea and Atmosphere, Avenida Brasília 1446-006 Lisboa, Portugal

$4{ }^{\mathrm{b}}$ Marine Biogeochemistry Group. Instituto de Investigaciones Marinas (CSIC). Vigo (Spain)

$5 \quad$ c University of Balearic Islands, Chemistry Department, Spain

6 *Corresponding author: jusae@iim.csic.es; tel. (+34) 986231930; fax(+34)986292762.

\section{Abstract}

8 Dissolved copper levels, copper complexing capacities and conditional stability constants have been determined in the Tagus estuarine waters and one of the saltmarshes located in this estuary, the Rosario saltmarsh. Tagus estuarine waters show a constant and around $20 \mathrm{nM}$ copper concentration during the estuarine mixing. Most of this copper is organically complexed by a strong ligand $\left(L_{1}\right)$ with a concentration that varies between 19-55 nM and a log $\mathrm{K}^{\prime}$ between 14.14-15.75. In addition L1/Cu ratios are quite constants and close to 1 all through the estuary, indicating the same source. A second and weakest ligand $\left(L_{2}\right)$ was also detected in these waters in higher concentrations (36-368 nM) but with a lower $\log \mathrm{K}^{\prime}$ that varies between 12.06-13.13. The present work has demonstrated that salt-marsh areas are important and continuous sources of copper complexing ligands to the Tagus estuary. Noticeable, tidal induced transport continuously feed these waters with copper and ligands, mainly with the strongest one. This continuous input, together with the high residence times of this system results in a quite constant concentration along the salinity gradient. This input represents $95 \%$ of the ligand present in the estuary.

Keywords: copper; ligands; speciation; estuary; salt-marsh; Tagus

\section{INTRODUCTION}

Salt-marshes are among the most common and extensive intertidal habitats along temperate coastlines. Several studies have shown that salt marshes incorporate large quantities of anthropogenic metals into the colonized sediments (Caçador et al., 1993; Sundby et al., 1998; Caetano et al., 2007). Root-sediment 
interactions appear to contribute to the metal enrichment of colonized sediments and belowground biomass (Caçador et al., 1993) as well as porewaters (Santos-Echeandía et al., 2010).

Not only the concentrations, but also trace metals chemical forms in estuarine water (porewater and water column) may control their bioavailability and toxicity. In the water column, speciation of many biologically active trace metals is controlled by complexation with strong organic ligands (Bruland et al., 1991). Copper (Cu) is probably the most studied metal in terms of organic complexation in seawater and estuarine environments. This is because copper is a micronutrient, but it is also toxic, for example for microalgae, at relatively low concentration levels. In addition, $\mathrm{Cu}$ forms complexes of relatively high stability with various organic ligands. However, no many studies about copper complexation in saltmarsh areas (Mucha et al., 2008) and its influence on the ligand budget of an estuary have been published till these days.

Several sources of organic matter and ligands to estuarine and coastal areas have been pointed out in the last years determining trace metal distribution along the salinity gradient (Laglera and van den Berg, 2003; Santos-Echeandia et al., 2008). In this way, autochthonous organisms are major producers of the ligands that dominate the complexing capacity of open ocean and coastal productive waters (Croot et al., 2000; Gordon et al., 2000). Organisms such as coccolithophores (Leal et al., 1999), cyanobacteria, dinoflagellates (Croot et al., 2000) and heterotrophic bacteria (Gordon et al., 2000) have been observed to excrete strong Cu-complexing ligands, most likely as a defense mechanism against metal toxicity. The input of terrestrial humic substances through riverine waters has also been recognized as an important source of strong ligands to estuarine environments (Kogut and Voelker, 2001; Shank et al., 2004a; Laglera et al., 2009).

Recent studies have shown that estuarine sediments can also act as a significant source of Cucomplexing ligands to the overlying water, which may strongly influence the biogeochemistry and cycling of dissolved Cu by sediment/water exchange (Skrabal et al., 1997, 2000; Shank et al., 2004b, Chapman et al., 2009). This source of organic ligands would be enhanced if sediments are colonized by plants (Mucha et al., 2008). In the last years, several studies conducted in salt marsh areas, have shown that as roots die they supply important quantities of organic matter to the sediment (Caçador et al., 2004; Pereira et al., 2007). In addition, low molecular weight organic acids are exudated by salt-marsh 

high affinity to organic matter.

As tidal water floods the salt marsh, large quantities of organic material, nutrients and trace metals accumulated in the area are exported to the estuary. On a semidiurnal tidal scale, advective fluxes are enhanced in salt marsh sediments (Santos-Echeandía et al., 2010) through a mosaic of small channels in the upper sediments. The relevance of the tidal induced transport on copper and complexing ligands may be crucial to understand the biogeochemical cycles of metals in coastal ecosystems where saltmarshes occupy large extensions.

Thus, the objectives of this work are: a) to measure dissolved copper and complexing ligand concentrations in the Tagus estuarine waters b) to determine dissolved copper and complexing ligand concentrations in the Rosário salt-marsh flooding and porewaters c) to estimate dissolved copper and ligand advective fluxes in the Rosário saltmarsh d) to ascertain the importance of this input over the Tagus estuarine waters.

\section{MATERIAL AND METHODS}

\subsection{Study area}

The $340 \mathrm{~km}^{2}$ of the Tagus estuary represent one of the largest transitional systems in Europe. The estuary is composed by a large shallow inner bay and a deep straight and narrow inlet channel (Fig. 1). This channel reaches a depth of $40 \mathrm{~m}$ and constitutes the deepest part of the estuary. The bay has a complex bottom topography with channels, tidal flats and islands. The deepest channel, with a water depth of 5-10 m, is an extension of the inlet channel. The total amount of water in the estuary is around $1.9 \mathrm{~km}^{3}$. The southern and eastern parts of the bay contain extensive inter-tidal mudflats; the northern part contains tidal flats, islands and several smaller channels. These channels merge upstream to a single narrow channel, marking the entrance of the Tagus River. pronounced dry season/wet season as well as large inter-annual variation. The average annual discharge is $\sim 400 \mathrm{~m}^{3} \mathrm{~s}^{-1}$, but seasonally the average monthly discharge may vary from $1 \mathrm{~m}^{3} \mathrm{~s}^{-1}$ to $>2200 \mathrm{~m}^{3} \mathrm{~s}^{-1}$ (Loureiro, 1979). Consequently, the residence time of freshwater in the estuary is highly variable and 
may range seasonally from 6 to 65 days (Braunschweig et al., 2003). The tides are semi-diurnal, with amplitudes at Lisbon ranging from $\sim 1 \mathrm{~m}$ at neap tide to $\sim 4 \mathrm{~m}$ at spring tide. The tidal effect reaches 80 $\mathrm{km}$ landward of the estuary mouth. Most pollutants are discharged from upper to the lower estuary (Fig. 1). Indeed, apart from being a major harbor, the fishing activities in the estuary are adversely affected by the inflow of effluents from about 3.5 million Greater Lisbon inhabitants, part of them untreated, coupled with industrial (chemicals and petrochemicals) and agricultural (fertilizers and pesticides) contributions.

Almost $40 \%$ of the estuary is composed by inter-tidal mudflats mainly in southern and eastern shores, containing extensive areas of salt marshes colonised mainly by Sarcocornia fruticosa, Sarcocornia perennis, Halimione portulacoides and Spartina maritima occupying an area around $20 \mathrm{~km}^{2}$. The marsh selected for this study (Rosário) is located in the southern shoreline of the estuary (Fig.1). It covers an area of $2 \mathrm{~km}^{2}$ (Crespo, 1993), being characterised by homogeneous stands of S. maritima as a pioneer species in the lower part, pure stands of $H$. portulacoides across the $20-50 \mathrm{~cm}$ elevation transect, and $S$. fruticosa and S. perennis in the higher salt marsh. The marsh is fully inundated twice a day by tidal action (2-4 $\mathrm{m}$ of tidal amplitude) through a highly branched system of channels that cross the elevation transect. The channels have 0.5-1.5 $\mathrm{m}$ depth promoting the inundation of the higher marsh even at low amplitude tides.

\subsection{Sampling}

A sampling cruise along the Tagus estuary was conducted on the $5^{\text {th }}$ May 2010. A $93 \mathrm{~m}^{3} \mathrm{~s}^{-1}$ flow was measured during that day what gives a residence time around 62 days for the water in the estuary (Braunschweig et al., 2003). Ten sub-surface water samples (TWB11-TWB410) were collected by hand in $1 \mathrm{~L}$ low density polyethylene (LDPE) bottles from a plastic boat (Fig. 1) during the low tide covering the salinity gradient of the estuary. In addition, flooding water during tidal inundation was sampled in two sites of the Rosário salt marsh (non-vegetated area and S.maritima colonised area and separated by less than $20 \mathrm{~m})$. At low tide, when sediment was exposed to the atmosphere, two sediment cores $(10 \mathrm{~cm}$ long) were collected at each site (vegetated and non-vegetated). The cores were sliced immediately after sampling in two $4 \mathrm{~cm}$ layers, prepared composite samples for each layer of the cores collected at each site, and material stored in acid pre-cleaned HDPE vials avoiding air presence inside. Sampling took 
place in less than $3 \mathrm{~min}$. Core material in the colonized area consisted of dense rooting sediments with no evidence of burrowing worms, crabs or bivalves. When tidal water starts to flood each site, flooding water was collected at each inundation time: 1, 5, 10, 15, 20 and $30 \mathrm{~min}$ for the non-vegetated area and

$1121,5,10,15,20,30,45$ and $85 \mathrm{~min}$ for plant colonized area. Flooding water was sampled $1 \mathrm{~cm}$ above the sediment surface directly into acid pre-cleaned syringes. The water and sediment samples were kept in refrigerated boxes and immediately transported to the laboratory. A more detailed description of these sampling procedures can be found in previous works (Caetano et al., 2007).

\subsection{Sample treatment}

Estuarine and flooding water samples were filtered through $0.45 \mu \mathrm{m}$ cellulose membranes placed in previously acid-cleaned filtration units (Nalgene). Filters were frozen and stored at $-20^{\circ} \mathrm{C}$ pending analysis of particulate copper and aluminium. The main reason for measuring particulate aluminium is that it acts as a tracer of lithogenic or terrigenous material (Windom et al., 1989; Pohl et al., 2004) and will be useful for the interpretation of the various sources of material to estuarine waters (i.e. rivers or sediment resuspension) (Mota et al., 2005).

Pore waters were separated from the sediment layers by centrifugation at 10,160 rcfxg for $30 \mathrm{~min}$ at +4 ${ }^{\circ} \mathrm{C}$ and filtered through $0.45 \mu \mathrm{m}$ cellulose acetate membranes. Filtration and subsequent manipulation of the samples were carried out in a glove box under argon atmosphere in order to avoid alteration of the initial conditions (Caetano et al., 2007; Santos-Echeandia et al., 2009). A portion of the filtered samples (around $200 \mathrm{~mL}$ ) was frozen for speciation analysis while around $100 \mathrm{~mL}$ were acidified with suprapure $\mathrm{HCl}(\mathrm{pH}<2)$ and stored pending analysis of total dissolved copper.

\subsection{Copper analysis in estuarine water}

\subsubsection{Total dissolved copper concentrations}

131 Copper analyses were carried out using voltammetric equipment (Metrohm 797 VA Computrace) 132 controlled by a computer (PC). The reference electrode was a double junction, $\mathrm{Ag} / \mathrm{AgCl}, \mathrm{KCl}(3 \mathrm{M})$, saturated $\mathrm{AgCl}$, with a salt-bridge filled with $3 \mathrm{M} \mathrm{KCl}$, and the counter electrode was a glassy carbon rod. concentration in the filtered samples was determined using a procedure similar to the one described 

acidification to $\mathrm{pH} 2.2$ by the addition of $10 \mu \mathrm{L} 6 \mathrm{M}$ bidistilled $\mathrm{HCl}$ (AnalR BDH) per $10 \mathrm{~mL}$ of sample in acid-cleaned borosilicate glass tubes. A $10 \mathrm{~mL}$ sample aliquot was pipetted into the voltammetric cell and ammonia (AristarGrade Merck) was used to ascertain the approximate neutralization of the $\mathrm{pH}$; also, HEPES buffer (BDH, final concentration 0.01 M) and Salycildoxime (SA, Sigma, final concentration of $25 \mu \mathrm{M} \mathrm{SA}$ ) were added. The solution was deaerated by purging $(5 \mathrm{~min})$ with nitrogen. The voltammetric parameters were: deposition $60 \mathrm{~s}$ at $-1.1 \mathrm{~V}$ whilst stirring, $8 \mathrm{~s}$ quiescence at $-0.1 \mathrm{~V}$, and a potential scan using the square-wave modulation: $10 \mathrm{~Hz}$, step height $2.5 \mathrm{mV}$, pulse height $25 \mathrm{mV}$, from 0 to $-0.8 \mathrm{~V}$. The sensitivity was calibrated by incorporating standard copper additions (Spectrosol BDH) to each sample. Each sample was analyzed in triplicate. A blank with Milli-Q water $(18.2 \mathrm{M} \Omega . \mathrm{cm})$ was made at intervals of every three samples and its concentration was subtracted in order to eliminate any copper contribution from reagents. Blank concentrations were around $0.27 \pm 0.06 \mathrm{nM}$.

\subsubsection{Copper titrations}

The copper complexing capacity of the waters of the Tagus estuary was determined by competing ligand exchange with adsorptive cathodic stripping voltammetry (CLE-AdCSV) of Cu-salycilaldoxime (SA) complexes according to previous works on copper complexation in estuarine waters (Campos and van den Berg, 1994; Laglera and Van Den Berg, 2003). Briefly, a 170-ml sample previously filtered by $0.45 \mu \mathrm{m}$ was transferred to a polyethylene bottle (Nalgene), and spiked with $\mathrm{HEPES} / \mathrm{NH}_{4} \mathrm{OH}$ buffer (for a concentration of $0.01 \mathrm{M}$ ) and SA (mix concentration of 5 or $10 \mu \mathrm{M}$ ). After stirring, $10 \mathrm{~mL}$ aliquots were pipetted into 15 polystyrene vials ( $30 \mathrm{~mL}$ Bibby, Sterilin) that were previously spiked with copper to provide increasing concentrations in the range of $0-700 \mathrm{nM}$ (actual range depending on the initial copper concentration and the ligand concentration to be determined). Prior to the first titration, the tubes were conditioned twice overnight with seawater containing the same range of copper concentrations in order to avoid copper loss in the tube walls. After that, aliquots of each sample were left to equilibrate overnight at room temperature due to the slow kinetics of the ligands and copper reactions (Campos and van den Berg, 1994). The equilibrium concentration of Cu-SA complexes was determined using the following parameters: adsorption potential of- $0.15 \mathrm{~V}$, deposition time of $60 \mathrm{~s}, 8 \mathrm{~s}$ 

and pulse height of $25 \mathrm{mV}$.

\subsubsection{Evaluation of complexing capacities and conditional stability constants}

167 Changes in the ratio between the concentrations of CuSA (labile to AdCSV) and CuL in the different aliquots permit the determination of the copper complexing capacity of the ligands present in solution $\left(\mathrm{C}_{\mathrm{L}}\right)$ and their conditional stability constant to bind copper $\left(\mathrm{K}_{\mathrm{CuL}}^{\prime}\right)$. A more detailed explanation can be found elsewhere (Ruzic, 1982; van den Berg, 1982). The relationship between the different copper fractions is described by the following transformation of the Langmuir isotherm:

$$
[\mathrm{Cu}]_{\mathrm{TOT}}=\Sigma\left(\mathrm{C}_{\mathrm{Li}}[\mathrm{Cu}]_{\mathrm{lab}} / \mathrm{K}_{\text {CuLia }}^{\prime}+[\mathrm{Cu}]_{\mathrm{lab}}\right)+[\mathrm{Cu}]_{\mathrm{lab}}
$$

$L_{i}$ represents the variability of the nature of the different natural ligands. Those ligands are differentiated according to the stability of their complexes with copper. $\alpha^{\prime}$ is the $\alpha$-coefficient of $\mathrm{Cu}^{2+}$ with inorganic ligands and SA. $[\mathrm{Cu}]_{\text {TOт }}$ and $[\mathrm{Cu}]_{\text {lab }}$ are respectively the total and labile copper concentrations related by:

$$
[\mathrm{Cu}]_{\mathrm{ab}}=\mathrm{i}_{\mathrm{p}} / \mathrm{S}
$$

Where $\mathrm{i}_{\mathrm{p}}$ is the voltammetric signal obtained from the reduction of the CuSA complexes adsorbed on the HMDE electrode and $\mathrm{S}$ is the ratio signal/concentration or sensitivity. $\mathrm{S}$ can be estimated from the slope of the last few points of the titration $\left(\mathrm{S}^{\mathrm{INT}}\right)$ if the titration has been extended to copper concentrations enough to complete the saturation of the natural ligands.

As indicated in the previous section, samples were analyzed using two different SA concentrations (5 and $10 \mu \mathrm{M})$. Higher SA concentrations increase the competing ability of SA. In the presence of complex mixes of ligands characterized by the formation of complexes with copper in a wide range of stability constants, the effect of increasing the SA concentration is both, an overcompetition of those ligands of low affinity for copper and the equilibration of SA with ligands of very high stability constant. Therefore, in heterogeneous matrices, the shift of the SA concentration resolves a different fraction of ligands, 
fraction that is defined as detection window. This is an important tool to estimate the heterogeniety of the pool of copper ligands in the sample.

Values for the stability constants of the complexes CuSA and $\mathrm{Cu}(\mathrm{SA})_{2}$ are necessary in order to obtain the value of $\alpha^{\prime}$ at each salinity. Both stability constant were calculated using relationships obtained in a previous work (Campos and van den Berg, 1994):

$$
\begin{aligned}
& \log K_{\mathrm{CuSA}}=(10.12 \pm 0.03)-(0.37 \pm 0.02) \log \text { salinity } \\
& \log \beta_{\mathrm{Cu}(\mathrm{SA}) 2}^{\prime}=(15.78 \pm 0.08)-(0.53 \pm 0.07) \log \text { salinity. }
\end{aligned}
$$

A plot of $\left[\mathrm{Cu}_{\mathrm{lab}}\right]$ vs the ratio $[\mathrm{Cu}]_{\mathrm{lab}} /[\mathrm{CuL}]$ is the most used procedure to solve $\mathrm{C}_{\mathrm{L}}$ and $\mathrm{K}^{\prime}{ }_{\mathrm{CuL}}$ from the slope and the $\mathrm{Y}$-axis value respectively. When only one ligand is present, the data follow a straight line but if more than one type of ligands are present, the plot takes a curved shape. In this case $\mathrm{C}_{\mathrm{L}}$ and $\mathrm{K}_{\text {CuL }}$ can be calculated with accuracy for a maximum of two types of ligands.

The estimation of $\mathrm{C}_{\mathrm{L} 1}, \mathrm{~K}_{\mathrm{CuL} 1}^{\prime}, \mathrm{C}_{\mathrm{L} 2}$ and $\mathrm{K}_{\mathrm{CuL2}}^{\prime}$ requires either an iterative refine procedure (Laglera-Baquer et al., 2001; van den Berg, 1982) or a nonlinear fitting (Gerringa et al., 1995). In the first case the solutions for $C_{L 1}$ and $K^{\prime}{ }_{C u L 1}$ are refined with estimations of $C_{L 2}$ and $K^{\prime}{ }_{C u L 2}$ from different linear sections of the plot until a convergent solution is obtained.

Complexing capacities, conditional stability constants and S can also be obtained fitting non-linearly the substitution of $\mathrm{Eq}(3)$ in $\mathrm{Eq}(1)$. Non-linear fitting prevents the uncertainty caused by the arbitrary necessity to split the titration data in two that iterative linear fitting requires.

In this work, we have used the fitting tool of a popular computer program, SigmaPlot (C) Systat Software, Inc) to fit 3, 4 or 5 parameters. The program uses a Levenberg-Marquardt fitting algorithm. We first solved the titration data sets for the hypothesis of a single ligand model using non-linear fitting incorporating $S$ as a parameter to $C_{L}$ and $K$. For this purpose, a new equation was incorporated to the Regression Wizard of the software under the "User-Defined" category. The Code fed to the Regression Wizard is presented in Table S1.

Then, we prepared a new Equation for the case of two types of ligands, i.e. 5 parameters $\left(\mathrm{C}_{\mathrm{L} 1}, \mathrm{~K}_{\mathrm{CuL1}}^{\prime}, \mathrm{C}_{\mathrm{L} 2}\right.$ and $\mathrm{K}_{\text {CuL2 }}^{\prime}$ and S) but the program struggled to offer realistic values in the form of very high $\mathrm{S}$ and $\mathrm{K}_{\text {CuL1 }}$ values. Removal of $S$ from the list of parameters and use of $S^{\text {INT }}$ did not solve problems with $K^{\prime}{ }_{\text {CuL1 }}$ for 
217 some titrations. In those cases, $\mathrm{K}_{\text {Cul1 }}$ was obtained from the iterative linear routine and its value fixed in

218 the constrains section of the code (Table S1) during the non-linear fitting of the rest of the complexing 219 parameters.

\subsubsection{Particulate copper and aluminum}

221 In order to determine the amount of labile copper, filters obtained from filtered water were subject to digestion overnight with $0.1 \mathrm{M}$ acetic acid in Teflon ${ }^{\circledR}$ vials (Savillex) at ambient temperature following the first step of the BCR extraction procedure (European Community Bureau of Reference; Quevauviller et al., 1997). The digest was then syringed-filtered $(0.45 \mu \mathrm{m})$ using a Swinnex filtration unit and stored pending analysis; filters containing the remnant particles were microwave digested using a mixture of $\mathrm{HF}$ and $\mathrm{HNO}_{3}(1: 3)$ in order to analyze the total fraction (Biscombe, 2004).

Labile copper determination was carried out by means of cathodic stripping voltammetry as explained before (Campos and van den Berg, 1994) while total particulate copper and aluminum determination was carried out with the standard additions method. Concentrations of $\mathrm{Al}$ and Cu were determined using a quadrupole ICP-MS (Thermo Elemental, X-Series) equipped with a Peltier Impact bead spray chamber and a concentric Meinhard nebulizer. Coefficients of variation for metal counts $(n=5)$ varied between 0.5 and $2 \%$. The precision and accuracy of each metal concentration measurements, determined through repeated analysis of certified reference material (PACS2), using Indium as internal standard, were 1-4\% and 2-5\%, respectively (data not shown). Procedural blanks always accounted for less than $1 \%$ of the total metal concentrations in samples.

\subsection{Estimation of sediment-water interchange: tidal induced fluxes}

As water floods over inter-tidal sediments the pore water solutes tend to be exported by advection and/or exchanged between mixing top sediments and tidal water. The associated pressure difference and tidal water movement are the driven mechanism for this transport. By using the temporal variation of copper and ligand concentrations in the flooding water the tidal induce transport $(T)$ to the water column is calculated using the following expression (Caetano et al., 2007).

$$
T=\Sigma\left[\left(C_{t+1}-C_{t}\right) /\left(2-C_{i}\right)\right]\left(h_{t+1}-h_{t}\right)
$$


where $C_{t+1}$ and $C_{t}$ are solute (copper and ligand) concentrations in the flooding water at times $t+1$ and $t$,

$244 C_{i}$ is the residual concentration (lowest value obtained for the flooding water) and ht and $h_{t+1}$ are the water depth at the same times. It was observed that water depth during the field measurements increased on the average 0.5 and $0.8 \mathrm{~cm}$ per minute of inundation in S. maritima and non-vegetated areas, respectively. The tidal induced transport of trace metals is calculated for the first 85 and 30 min of inundation, respectively. Since inter-tidal sediments are inundated twice a day, the tidal induce transport $(T)$ was multiplied by a factor of two to present values on a daily basis.

\section{RESULTS}

\subsection{Determination of the complexing parameters and the sensitivity by non-linear fitting}

Table 1 shows the complexing parameters found for the estuarine water samples according to one and two ligands models. Table 2 shows those parameters for flooding waters and interstitial waters extracted from cores. For the one ligand model, $\mathrm{S}$ was added to the fitting procedure according to the

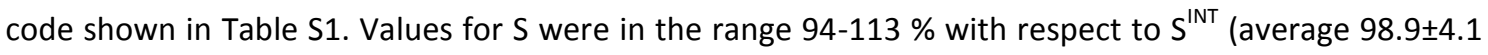
\%) indicating that any bias due to undersaturation of the ligands present in the sample caused by a too small copper concentration at the end of the titration was masked by the analytical error. For the sample collected at station $11, \mathrm{~S}$ was fitted at a very low value $90 \%$ of $S^{\mathrm{INT}}$ and the complexing parameters were recalculated using $\mathrm{S}^{\mathrm{INT}}$.

For the two ligands model, this approach was not possible as explained above. For some titration sets, $\mathrm{S}$ was estimated to be $103-114 \%$ of $S^{\text {INT }}$ but for many others this correction reached as much as $170 \%$ which could be discarded simply by visual inspection. Values in Table 2 were obtained using $s^{\text {INT }}$. When the estimation of $K_{\text {Cul1 }}^{\prime}$ produced a value over 20 , the titration data set was solved by iterative linear fitting (Laglera-Baquer et al., 2001; Laglera and Van Den Berg, 2003) and the value of $K_{\text {CuL1 }}^{\prime}$ fixed on the constrains section of the code. This led to a 3 parameters non-linear fitting. An extensive description of separate work (Laglera et al., 2012). 
271 Dissolved copper concentrations along the salinity gradient in the Tagus estuary are plotted in Fig. 2 a.

272 With the exception of the station located upstream in the river (26.4 nM), values were quite constants

273 and around $20 \mathrm{nM}$ all over the estuary. The ligand concentration ( $\mathrm{L}$; Fig. 2a), for the $5 \mu \mathrm{M}$ SA detection

274 window, showed higher values in riverine samples (399 nM) decreasing to 320-340 nM in the first 3

275 units of salinity. A new decay is found from salinity 5 to 25 (to $46 \mathrm{nM}$ ). This decreasing trend from fresh

276 to marine waters has been observed before in other estuarine systems (Laglera et al., 2003; Plavsic et

277 al., 2009). The conditional stability constant for these ligands (log K') ranges between 12.20 and 13.26

278 (Table 1), and it presents a bowl-shape distribution along the salinity gradient, with lower values in the 279 mid-estuary and maxima at marine (13.26) and riverine (13.11) end-members.

280 By fitting data to two types of ligands, a strong $\left(L_{1}\right)$ and a weak $\left(L_{2}\right)$ one can be observed in the Tagus estuary waters (Fig. 2a). Ligand $L_{1}$ varied between 14 and $55 \mathrm{nM}$ being the highest concentration found in the two most riverine stations. Values decreased sharply to $15 \mathrm{nM}$ at salinity 3 remaining almost constant until the marine end member (salinity 25). Otherwise, $L_{2}$ concentrations vary between 36 and $368 \mathrm{nM}$ with a conservative distribution between salinities 5 and 25, but with lower values than expected for an ideal dilution line between salinities 0 and 5 . The conditional stability constants for these ligands range between 14.10 and 15.75 for $L_{1}$ and between 12.06 and 13.13 for $L_{2}$ (Table1). The distribution along the salinity gradient is different among them; while $\log K_{1}^{\prime}$ shows a saw tooth tendency with higher values in the riverine end-member, $\log K_{2}^{\prime}$ distribution is comparable to log $K^{\prime}$, with the lowest values in the mid estuary and increasing towards the river (13.13) or the sea (12.42) end members.

In order to detect stronger copper complexing ligands and check for homogeneity/heterogeneity of them in the estuary (van den Berg and Donat, 1992; Buck and Bruland., 2005; Santos-Echeandia et al., 2008), a detection window of $10 \mu \mathrm{M}$ SA has been applied to some of the samples. Samples, fitted to one ligand are plotted in Fig. 2b. Ligand concentration increases between salinity 0 and 5 (from 121 to 142 $\mathrm{nM}$ ) and progressively decreases to $30 \mathrm{nM}$ at salinity 25 with a quite linear trend. The conditional stability constant (log $\left.K^{\prime}\right)$ presented, again, lower values at mid salinities (13.11) increasing towards the riverine (14.52) and marine (13.76-14.15) end members (Table 1) as observed for the lower detection 
window $\left(5 \mu \mathrm{M}\right.$ SA). By fitting data to two types of ligands, the strongest one $\left(\mathrm{L}_{1}\right)$ concentrations ranged between 15 and $28 \mathrm{nM}$ (Fig. 2b) with a quite irregular distribution. On the contrary, the weakest ligand of this detection window $\left(L_{2}\right)$ shows a similar trend to $L$, with an initial increased from 145 to $174 \mathrm{nM}$ decreasing progressively afterwards to $22 \mathrm{nM}$ at salinity 25 . The conditional stability constants, both log $K_{1}^{\prime}$ and $\log K_{2}^{\prime}$ present higher values at low salinities (16.84 for $K_{1}$ and 13.87 for $K_{2}$ ) that sharply decreased at salinity 5 reaching 15.02 for $\log \mathrm{K}_{1}{ }^{\prime}$ and 12.76 for $\log \mathrm{K}_{2}{ }^{\prime}$ remaining relatively constant towards the marine end-member (Table 1).

Suspended particulate matter values oscillate between 4.8-14.7 $\mathrm{mg} \mathrm{L}^{-1}$ in the estuary with an irregular distribution (Fig. S1a). The highest values where found at salinities 10-15 and the lowest between salinities 19-23. Particulate copper concentrations varied between 0.78 and $14.8 \mathrm{nM}$ (Fig. S1b). The highest levels were found at mid-salinities (5-15 ups) while the lowest values measured at both endmembers. The labile copper in the particulate matter accounts only for the $0.05-0.45 \%$ of the total copper but it is noticeable that the lability was higher for the lowest salinities (Fig. S1c). Particulate aluminum concentrations ranged between 272 and $4930 \mathrm{nM}$ with a similar distribution to particulate copper.

\subsection{Dissolved copper and its organic speciation in the Rosario Saltmarsh}

\subsubsection{Flooding waters}

317 Dissolved copper concentrations in the flooding water in the two sites of the salt marsh (non-vegetated

318 and plant colonized areas) are plotted in Fig. 3a. Copper levels in the non-vegetated zone increase 1 minute after arriving of tide water from 18.3 to $28.5 \mathrm{nM}$. In the following 5 minutes, levels decreased reaching $20.6 \mathrm{nM}$ and remaining quite constant until 30 minutes after tidal inundation started, with the exception of minute 15 when a less pronounced increase $(27.0 \mathrm{nM})$ was observed (Fig. 3a). In a similar way, dissolved copper levels increased in the colonized area 1 minute after the flood started reaching higher values (32.5 nM) than in the non-vegetated area. Afterwards, concentrations decreased to 17.7 $\mathrm{nM}$ and varied irregularly between 13.6 and $22.1 \mathrm{nM}$ during the next 80 minutes of inundation. 
The time course evolution of ligand concentration in the flooding waters is also plotted in Fig. 3a. A net increase of its concentration (initial levels of $46 \mathrm{nM}$ ) was observed in both sampling areas but reaching higher concentrations in the plant colonized (291 nM) than in the non-vegetated area ( $85 \mathrm{nM})$ during the first minute of inundation. Afterwards levels in plant colonized sediments decreased sharply while in non-vegetated area values diminished progressively reaching, at both areas similar values to those found before inundation started. The conditional stability constants of ligand showed higher values in the non-vegetated (13.73-14.04) than in the plant colonized area (13.11-13.89) (Table 2). The significance for statistical analyses was $p<0.05$.

In addition, the time course evolution of log $\mathrm{K}^{\prime}$ values during the tidal inundation were different among the two sites: while an increase of log $\mathrm{K}^{\prime}$ was found one minute after the inundation started in the nonvegetated area, a progressive increase of log $\mathrm{K}^{\prime}$ with time was observed in the vegetated area during the first 10 minutes.

The strongest ligand $\left(\mathrm{L}_{1}\right)$ concentrations vary between 46 and $61 \mathrm{nM}$ in the non-vegetated area without a trend all over the time (Fig. 3b). Nevertheless, $\mathrm{L}_{1}$ concentrations in the colonized area are more variable and ranged between 28 and $95 \mathrm{nM}$. The conditional stability constant of this ligand varied between 14.12 and 14.79 in the non-vegetated area while in the colonized area a variation between 13.61 and 14.83 was found (Table 2). The weakest ligand concentrations were higher and varied between 60 and $107 \mathrm{nM}$ for the non-vegetated area and from 5.5 to $258 \mathrm{nM}$ for the colonized area (Fig. $3 b)$. It is noticeable the net increase in the colonized area in the first minutes of inundation that is not observed in the non-vegetated area. Finally, conditionals stability constant for this weakest ligand oscillate between 11.95-12.26 nM in the non-vegetated area and 11.87-13.05 in the colonized area (Table 2).

Strongest ligands have been detected in the flooding waters moving the detection window to $10 \mu \mathrm{M}$ SA. Ligand concentration were lower (61-87 nM) in the non-vegetated area than in the colonized site (107$137 \mathrm{nM}$ ) during the first 5 minutes of inundation (Fig. 3c). An increase was found in the first minute comparing to the estuarine waters in the vicinity of the salt-marsh and concentrations slightly decrease after 5 minutes. The respective conditional stability constants were similar in the non-vegetated area (14.39-14.48 nM) and in the plant-colonized area (14.32-14.47 nM) (Table 2). 

and $82 \mathrm{nM}$ for $L_{1}$ and from 59 to $138 \mathrm{nM}$ for $L_{2}$ with a similar trend to the unique ligand (L). However, $L_{1}$ levels do not decrease after 5 minutes but continue to increase (Fig. 3c). Conditional stability constants ranged in the following intervals: $14.63-15.69$ for $L_{1}$; and 12.84-13.44 for $L_{2}$ (Table 2).

\subsubsection{Porewaters.}

Dissolved copper and ligand concentrations and their conditional stability constants in the porewaters of the salt-marsh are shown in Table 3. Levels of dissolved copper in the non-vegetated area ranged from 45.3 to $53.9 \mathrm{nM}$ with higher values in the upper layer than in the deeper one. However, higher ligand concentrations were found in deeper porewaters (321 nM) than in surface ones (245 nM). The conditional stability constants for these ligands varied between 13.24 for the deeper layer and 13.58 for the upper one. Levels of the stronger ligand $\left(L_{1}\right)$ ranged from 77 to $184 \mathrm{nM}$ with higher values in the upper layer. Nevertheless, the conditional stability constant was higher (14.77) in the deeper layer than in the upper one (13.70). Concentrations of $L_{2}$ varied between 70 and $287 \mathrm{nM}$ with increased values in the deeper layer. The conditional stability constants of this weakest ligand were 12.68 for the deeper layer and 13.09 for the upper one.

Higher dissolved copper concentrations in pore waters (71-142 nM) were found in the plant colonized area (Table 3). Ligand concentrations vary between $767 \mathrm{nM}$ in the deeper layer and $831 \mathrm{nM}$ in the upper one. Conditional stability constant for this ligand showed higher values in the upper layer. The stronger ligand, $L_{1}$, levels varied between 115 and $203 \mathrm{nM}$ with higher values in the upper layer and their conditional stability constants were 15.17 for the upper layer and 14.66 for the deeper one. Concentrations of $L_{2}$ were quite similar among layers (666 and $699 \mathrm{nM}$ ) as the conditional stability constants (13.09 and 12.82).

Strongest ligands in pore waters were found by applying a higher detection window (10 $\mu \mathrm{M})$ (Table 3). Ligand concentration in the non-colonized area was $230 \mathrm{nM}$ with a conditional stability constant of 14.28. A strong ligand with a $\log \mathrm{K}_{1}{ }^{\prime}$ of 15.25 and a concentration of $67 \mathrm{nM}$ and a weak ligand with a log $\mathrm{K}_{2}{ }^{\prime}$ of 13.85 and a concentration of $182 \mathrm{nM}$ result from the data fitting to two types of ligands. As found with the $5 \mu \mathrm{M}$ SA detection window, higher values were observed in the vegetated area at $10 \mu \mathrm{M}$ detection window. A ligand concentration of $419 \mathrm{nM}$ with a log $\mathrm{K}^{\prime}$ of 13.95 was registered. In the data 
381 fitting to two types of ligands, a strong ligand concentration of $148 \mathrm{nM}$ with a log $\mathrm{K}_{1}^{\prime}$ of 17.56 was

382 recorded, while the weakest ligand showed a concentration of 846 with a log $K_{2}^{\prime}$ of 13.51.

383

384

385

386

387

388

389

390

391

392

393

394

395

396

397

398

399

400

401

402

403

404

405

406

407

\subsection{Tidal induced transport of copper and organic ligands in the Rosario Saltmarsh}

An estimation of the tidal induced transport of dissolved copper and ligands is shown in Table 4. A flux of $1.23 \mu \mathrm{mol} \mathrm{m} \mathrm{m}^{-1}$ of dissolved copper escapes from the sediment to the overlying waters in the nonvegetated area, while the ligand transport was $3.25 \mu \mathrm{mol} \mathrm{m} \mathrm{m}^{-1}$. If the two ligand case is considered, an export of $2.16 \mu \mathrm{mol} \mathrm{m} \mathrm{m}^{-2}$ of the strongest ligand and $2.31 \mu \mathrm{mol} \mathrm{m} \mathrm{m}^{-1}$ of the weakest one was estimated. As expected from the results shown in previous sections calculated transports are higher in the plant colonized area, where a $2.43 \mu \mathrm{mol} \mathrm{m} \mathrm{d}^{-1}$ flux of dissolved copper is estimated. The ligand flux $\left(48.2 \mu \mathrm{mol} \mathrm{m} \mathrm{d}^{-1}\right)$ was around fifteen times higher than in the non-vegetated area. Increased transport of both strong and weak ligand to the water column was also found with $11.5 \mu \mathrm{mol} \mathrm{m} \mathrm{d}^{-1}$ for $\mathrm{L}_{1}$ and $64.7 \mu \mathrm{mol} \mathrm{m} \mathrm{d}^{-1}$ for $\mathrm{L}_{2}$.

The tidal induced transport of ligands detected by the $10 \mu \mathrm{M}$ SA detection window was similar in the non-vegetated area and lower in the colonized area. In this way, $4.25 \mu \mathrm{mol} \mathrm{m} \mathrm{m}^{-1}$ of ligands were exported in the non-colonized area while $6.87 \mu \mathrm{mol} \mathrm{m} \mathrm{m}^{-2} \mathrm{~d}^{-1}$ were exported in the plant colonized area. For the two ligand case, $3.80 \mu \mathrm{mol} \mathrm{m} \mathrm{d}^{-1}$ of the strongest ligand and $5.77 \mu \mathrm{mol} \mathrm{m} \mathrm{d}^{-1}$ of the weakest one were estimated.

\section{DISCUSSION}

\subsection{Copper and organic ligands behavior during the estuarine mixing}

Dissolved copper and complexing ligand behavior in the Tagus estuary can be clearly divided in two distinct chemical areas. The edge is marked by the salinity 5.6 sample. In the low salinity stretch, although dissolved copper values were only higher in the most riverine sample, the strong ligand values $\left(L_{1}\right)$ were higher than in the rest of the estuary. As a consequence the $L_{1} / C u$ ratio is relatively constant and around 1. The only exceptions are the two most riverine stations (Fig. S2) where an excess of $L_{1}$, which may derived from the river end member was detected. This ratio is linear and progressively decreases with the increasing salinity if total ligand concentration is considered (Fig. S2). Moreover, the weakest ligand $\left(L_{2}\right)$ also showed a different behavior in this zone of the estuary but with lower levels 
than expected if the trend marked by the seven most saline stations is extended to the freshwater endmember.

The mixing of freshwater with the marine water dilutes $L_{1}$ ligand within the estuarine area. The long residence times (Braunschweig et al., 2003), confirmed by uniform suspended particulate matter content in a wide salinity range (Fig. S1a), allow the homogenization of the water body justifying the constancy of copper and strong ligand levels in the 6-25 salinity range. This pattern suggest that the tidal effect superimposes the river flow and no losses of copper or strong ligands occured during the estuarine mixing. Similar findings have been observed in the Scheldt estuary by Laglera and van den Berg (2003). A continuous lateral input, as detected in the Vigo Ria (Santos-Echeandía et al., 2008), in the Tagus estuary may also explain the constant values all over the salinity gradient. In addition, this area shows constant and close to the unit $\mathrm{L}_{1} / \mathrm{Cu}$ ratios in a wide salinity range (Fig. S2). This means that copper and $L_{1}$ levels are similar probably because their source is the same. There is no evidence of copper transfer from the dissolved to the particulate fraction since values were quite low all through the estuary (Fig. S1b). However, $\mathrm{L}_{2}$ experiments a progressive decrease in their levels towards the outer part of the estuary and no remarkable inputs of $L_{2}$ are observed at mid-high salinities as observed for $L_{1}$. It can be assumed that the river is not the major source of this weak ligand, but its origin is somewhere in between salinities $0-6$, where although the mixing with seawater, its concentration remains constant or even increases. This increase is consistent with the trend observed at both detection windows for the weakest ligand (Fig. 2). The higher particulate aluminum concentrations at salinities 6-10 (Fig. S1c) and SPM at salinity 10 could reflect the maximum turbidity zone in this salinity gradient and at spring tides the bottom particle resuspension in this area may explain the release of the weakest ligand from the sediments (Shank et al., 2004; Santos-Echeandia et al., 2008). If copper variability during the estuarine mixing is associated to $L_{1}, L$ behavior is ruled by $L_{2}$. This fact is supported by the spatial distribution of log $\mathrm{K}_{2}^{\prime}$, which is quite similar to $\log \mathrm{K}^{\prime}$ (Table 1$)$ at both detection windows $(5 \mu \mathrm{M}$ y $10 \mu \mathrm{M})$. of the stronger ligand $\left(L_{1}\right)$ was homogeneous, mainly at high salinities, because the log $K_{1,5 \mu \mathrm{MSA}}^{\prime}$ and log $\mathrm{K}_{1,10 \mu \mathrm{MSA}}^{\prime}$ were similar (Table 1 ) and, in general, their ratio was close to 1 (Fig.S3a). Moreover, ratios between $L_{1}$ measured at the low detection window and the $L_{1}$ observed at the high detection window 
437 and a shift to the higher detection window induces the decrease of the ligand concentrations. Thus, the ratio between $L_{2}$ measured at low detection window and at high detection window is around 2

$439(2.09 \pm 0.48)$ (Fig. S3b). An increase of the log $\mathrm{K}^{\prime}$ values is also observed when moving the detection window to $10 \mu \mathrm{M}$ SA. As a consequence the ratios between log K'at high and low detection windows are always well below 1 all over the salinity gradient (Fig. S3a).

\subsection{Saltmarsh inputs of copper and complexing ligands to the estuary} to estuarine waters. Mucha et al. (2008) demonstrated that salt-marsh plants are able to produce relatively high amounts of strong $\mathrm{Cu}$-complexing ligands in their root system and the present study evidenced that these complexes are exported to estuarine waters through tidal induced transport (Table 4).

The constant dissolved copper and $L_{1}$ concentrations in a wide salinity gradient (6-25) is presumably explained by the lateral input from the marsh areas along the gradient coupled with high residence time of water in the estuary. Previous studies have showed that copper levels in the adjacent area to the Tagus ( $\mathrm{S} \geq 30$ ) varied between 1.6 and 14.6, well below the values found at salinity 25 (Cotté-Krieff et al.,

452 2000; Santos-Echeandia et al., 2012). The correlation between $\mathrm{Cu}$ and $\mathrm{L}_{1}(r=0.67, \mathrm{p}<0.05)$ in the Tagus estuarine waters suggest that the source of copper and ligands at mid-salinities is diluted at high salinities. The inexistence of marshes downstream the inlet that connects the estuary to the sea reinforces the hypothesis that salt marshes are the main source of copper and complexing ligands. Moreover, the conditional stability constants for $L_{1}$ in the waters exported from the salt-marsh $(14.34 \pm 0.27$ for the non-colonized area and $14.17 \pm 0.41$ for the vegetated area) are comparable to the ones present in the estuary $(14.38 \pm 0.37)$. for the non-colonized area and $12.29 \pm 0.46$ for the vegetated area) are similar to those present in the estuary, the input through tidal cycles is not reflected in the estuarine distribution of the weak ligand. As

462 shown before, $L_{2}$ concentrations decrease towards higher salinities. A photo-degradation process during 
464

465

466

467

468

469

470

471

472

473

474

475

476

477

478

479

480

481

482

483

484

485

486

487

488

489

490

$\mathrm{mg} \mathrm{L}^{-1}$ against 22-99 $\mathrm{mg} \mathrm{L}^{-1}$ for the Scheldt estuary, Zwolsman and van Eck., 1999) is a possible explanation. The high residence time of the waters in the Tagus estuary would favor this degradation as shown in the Scheldt estuary (Laglera and van den Berg., 2006). According to these authors $L_{2}$ is more susceptible to photo-degradation than $L_{1}$, as the former is stabilized by its complexation with copper. In addition, due to the heterogeneous distribution of this ligand, it is possible that several sources (i.e. harbor, untreated effluents) contribute to the pool of weak ligands.

Considering the water volume of the Tagus estuary $\left(1.9 \times 10^{9} \mathrm{~m}^{3}\right)$, the residence time during the sampling conditions (60 days), the area covered by the intertidal non-vegetated zones $\left(128 \mathrm{~km}^{2}\right)$ and salt marshes $\left(20 \mathrm{~km}^{2}\right)$ and the tidal induce transport of copper and ligands from the sediment to the water column in the Rosário salt-marsh (Table 4), a contribution of around $7 \mathrm{nM}$ of copper, $16 \mathrm{nM}$ of $\mathrm{L}_{1}$ and $52 \mathrm{nM}$ of $\mathrm{L}_{2}$ to the Tagus estuarine waters has been estimated. This account for $35 \%$ of $\mathrm{Cu}, 94 \%$ of $\mathrm{L}_{1}$ and $45 \%$ of $\mathrm{L}_{2}$ present in the estuary $(\mathrm{S} \geq 6)$.

This continuous input of copper complexing ligands is beneficial for the health of the estuary. Several inputs of copper coming from a variety of sources, especially in such an industrialized and populated area as it is the Tagus estuary can be neutralized by its binding to natural ligands. This would decrease its toxicity to living organisms when an extra input of copper occurs (Louis et al., 2009).

\section{CONCLUSIONS}

Tagus estuarine waters show a relatively constant copper concentration during the estuarine mixing. Most of this copper is organically complexed by a strong ligand $\left(L_{1}\right)$ all through the estuary. A second and weakest ligand $\left(L_{2}\right)$ was also detected in these waters in higher concentrations. Salt-marsh areas are the major sources of copper complexing ligands to the Tagus estuary. Noticeable, tidal induced transport continuously feed estuarine waters with copper and ligands, mainly with the strongest one. Its input can represent $95 \%$ of the ligand present in the estuary. Salt-marsh input of copper complexing ligands determines copper distribution along the salinity gradient of the Tagus estuary.

Although future research should be performed to compare the importance of this source of ligands with other sources like urban effluents, rivers or benthic inputs, the present work has demonstrated that salt marsh areas are the main inputs of copper complexing ligands to the Tagus estuary. 
491

492

493

494

495

496

497

498

499

500

501

502

503

504

505

506

507

508

509

510

511

512

513

514

515

This type of fluxes should be taken into account when assessing trace metal contamination problems and remediation in estuarine and coastal areas. Furthermore, one may speculate that inundation of coastal areas associated with the climatic changes, either to increase of water levels or floods will result in additional fluxes of trace elements and copper complexing ligands from inter-tidal areas to estuarine and coastal waters. The relevance of the tidal induced transport on copper and complexing ligands coming from salt marsh areas may be crucial to understand the biogeochemical cycles of metals in coastal ecosystems all over the world where salt-marshes occupy large extensions.

Aknowledgements. The authors would like to thank Vasco, Rute and Antonio for their kind sampling cooperation during the sampling campaign. The C.S.I.C., under the program JAE-Doc (Junta para la Ampliación de Estudios) co-funded by the European Social Fund (ESF), is greatly acknowledged for the post-doctoral contract to J. Santos-Echeandía.

\section{REFERENCES}

- Biscombe., 2004. Factors influencing the seawater solubility of aerosol associated trace metals. PhD Thesis. University of Plymouth.

- Braunschweig, F., Martins, F., Chambel, P., Neves, R., 2003. A methodology to estimate renewal time scales in estuaries: the Tagus Estuary case. Ocean Dynamics 53, 137-145.

- Bruland, K.W., Donat, J.R., Hutchins, D.A., 1991. Interactive influences of bioactive trace metals on biological production in oceanic waters. Limnology and Oceanography 36, 1555-1577.

- Buck, K., Bruland, K., 2005. Copper speciation in San Francisco Bay: a novel approach using multiple analytical windows. Marine Chemistry 96, 185-198.

- Caçador, I., Costa, A., Vale, C., 2004. Carbon Storage in Tagus Salt Marsh Sediments. Water Air Soil Pollution: Focus 4, 701-714.

- Caçador, I., Vale, C., Catarino, F., 1993. In: Vernet, J.-P. (Ed.), Environmental contamination. Studies in Environmental Sciencevol. 55. Elsevier, Amsterdam, pp. 355-365. 

content and stable isotopic signature Science of the Total Environment 380, 84-92. water by cathodic stripping voltammetry and ligand competition with salicylaldoxime Analytica Chimica Acta 284, 481-496. complexing ligands and thiol compounds in shallow lagoon waters. Marine Environmental Research 67, 17-24.

524 - Cotté-Krieff, M.H., Guieu, C., Thomas, A.J., Martin, J.M., 2000. Sources of $\mathrm{Cd}, \mathrm{Cu}, \mathrm{Ni}$ and $\mathrm{Zn}$ in Portuguese coastal waters. Marine Chemistry 71 (3-4), 199-214.

- Crespo, R., 1993. Cartografia do habitat potencial de passeriformes no Estuário do Tejo por processamento digital de imagem. Degree Thesis. Faculdade de Ciências - Universidade de Lisboa, Portugal, pp. 124.

- Croot, P.L., Moffet, J.W., Brand, L.E., 2000. Production of extracellular Cu complexing ligands by eucaryotic phytoplankton in response to Cu stress. Limnology and Oceanography 45, 619-627.

531 - Gerringa, L.J., Herman, P.M., Poortvliet, T.C., 1995. Comparison of the linear Van den Berg/Ruzic transformation and a non-linear fit of the Langmuir isotherm applied to $\mathrm{Cu}$ speciation data in the estuarine environment. Marine Chemistry 48, 131-142.

534 - Gordon, A.S., Donat, J.R., Kango, R.A., Dyer, B.J., Stuart, L.M., 2000. Dissolved copper-complexing 535 ligands in cultures of marine bacteria and estuarine water. Marine Chemistry 70, 149-160.

536 - Kogut, M.B., Voelker, B.M., 2001. Strong copper-binding behavior of terrestrial humic substances in 537 seawater. Environmental Science and Technology 35, 1149-1156.

538 - Laglera-Baquer, L.M., González-Dávila, M., Santana-Casiano, J.M., 2001. Determination of metallic 539 complexing capacities of the dissolved organic material in seawater. Scientia Marina 65, 33-40. 

waters. Marine Chemistry 82 (1-2), 71-89. ligands in estuarine waters. Marine Chemistry 101 (1-2), 130-140. substances in seawater. Limnology and oceanography 54, 610-619. fitting for the estimation of complexing parameters from metal titrations of estuarine samples. Analytica Chimica Acta, submitted. ligands similar to thiols by Emiliania huxleyi in seawater cultures. Limnology and Oceanography 44, $1750-1762$. equilibrium studies of copper-dissolved organic matter complexation in water column of the stratified Krka River estuary (Croatia). Marine Chemistry 114, 110-119. Servicio Hidraulico (DGRAH), Lisbon (1979). in the Tagus Estuary. Water Research 39, 1451-1460.

559 - Mucha, A.P., Almeida, C.M.R., Bordalo, A.A., Vasconcelos, M.T.S.D., 2010. LMWOA (low molecular weight organic acid) exudation by salt marsh plants: Natural variation and response to $\mathrm{Cu}$ contamination Estuarine, Coastal and Shelf Science 88, 63-70. maritimus and Scirpus maritimus) as sources of strong complexing ligands Estuarine, Coastal and 

metal dynamics in salt marshes (Tagus Estuary, Portugal) Science of the Total Environment 380, 93-101.

- Pohl, C., Löffler, A., Hennings, U., 2004. A sediment trap flux study for trace metals under seasonal aspects in the stratified Baltic Sea (Gotland Basin; $57^{\circ} 19.20^{\prime} \mathrm{N} ; 2^{\circ} 03.00^{\prime} \mathrm{E}$ ). Marine Chemistry $84,143-160$.

- Plavsic, M., Kwokal, Z., Strmecki, S., Peharec, Z., Omanovic, D., Branica, M. Determination of the copper complexing ligands in the Krka rivers estuary. Fresenius Environmental Bulletin 18(3), 327-334.

573 - Quevauviller, P., Rauret, G., Rubio, R., Lopez-Sanchez, J.F., Ure, A., Bacon, J., Muntau, H., 1997. 574 Certified reference materials for the quality control of EDTA- and acetic acid-extractable contents 575 of trace elements in sewage sludge amended soils (CRMs 483 and 484). Fresenius Journal of Analytical Chemistry 357, 611-618.

577 - Ruzic, I., 1982. Theoretical aspects of the direct titration of natural waters and its information yield for trace metal speciation. Analytica Chimica Acta 140, 99-113.

579 - Santos-Echeandía, J., Laglera, L.M., Prego, R., van den Berg, C.M.G., 2008. Copper speciation in estuarine waters by forward and reverse titrations. Marine Chemistry108 (3-4), 148-158.

- Santos-Echeandia, J., Laglera, L.M., Prego, R., van den Berg, C.M.G., 2008. Dissolved copper speciation behaviour during estuarine mixing in the San Simon Inlet (wet season, Galicia). Influence of particulate matter. Estuarine Coastal and Shelf Science76, 447-453. Galician Ria (NW Iberian Peninsula): implications for benthic fluxes of dissolved trace elements (Co, $\mathrm{Cu}, \mathrm{Ni}, \mathrm{Pb}, \mathrm{V}, \mathrm{Zn}$ ). Marine Chemistry 117, 77-87. metal distribution in pore waters of marsh sediments and its transport to water column (Tagus estuary, Portugal) Marine Environmental Research 70, 358-367. 

metal baselines in coastal waters at a regional scale: The case of the Portuguese coast (SW Europe). Marine Environmental Research, in press.

- Shank, G.C., Skrabal, S.A., Whitehead, R.F., Kieber, R.J., 2004a. Strong copper complexation in an organic-rich estuary: the importance of allochthonous dissolved organic matter. Marine Chemistry 88, 21-39.

- Shank, G.C., Skrabal, S.A., Whitehead, R.F., Kieber, R.J., 2004b. Fluxes of strong Cu-complexing ligands from sediments of an organic-rich estuary. Estuarine Coastal and Shelf Science 60 (2): 349-358.

- Skrabal, S.A., Donat, J.R., Burdige, D.J., 1997. Fluxes of copper-complexing ligands from estuarine sediments. Limnology and Oceanography 42, 992-996.

- Skrabal, S.A., Donat, J.R., Burdige, D.J., 2000. Pore water distributions of dissolved copper and coppercomplexing ligands in estuarine and coastal marine sediments. Geochimica et Cosmochimica Acta 64, 1843-1857. on the roots of salt marsh plants: Mechanism and rate of formation. Limnology and Oceanography 43, 245-252.

606

- Turoczy, N.J., Sherwood, J.E., 1997. Modification of the van den Berg/ Ruzic method for the investigation of complexation parameters of natural waters. Analytica Chimica Acta 354 (1-3),

- Van den Berg, C.M.G., 1982. Determination of copper complexation with natural organic ligands in seawater by equilibration with $\mathrm{MnO} 2 \mathrm{I}$. Theory. Marine Chemistry 11 (4), 307-322. windows. Analytica Chimica Acta 257 (2), 281-291. 

southeastern United States. Environ. Sci. Technol. 23, 314-320.

617 - Zwolsman, J.J.G., van Eck, G.T.M., 1999. Geochemistry of major elements and trace metals in

Netherlands. Marine Chemistry 66 (1-2), 91-111. 


\section{Salt-marsh areas as copper complexing ligand sources to estuarine and coastal systems}

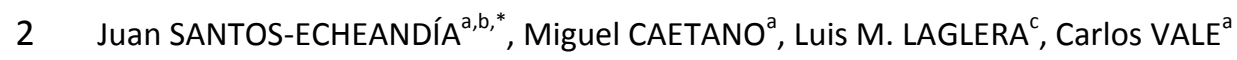

3 a IPMA, Portuguese Institute of Sea and Atmosphere, Avenida Brasília 1446-006 Lisboa, Portugal

$4{ }^{b}$ Marine Biogeochemistry Group. Instituto de Investigaciones Marinas (CSIC). Vigo (Spain)

$5 \quad$ c University of Balearic Islands, Chemistry Department, Spain

$6 \quad *$ Corresponding author: jusae@iim.csic.es; tel. (+34) 986231930; fax(+34)986292762.

\section{Abstract}

8 Dissolved copper levels, copper complexing capacities and conditional stability constants have been determined in the Tagus estuarine waters and one of the saltmarshes located in this estuary, the Rosario saltmarsh. Tagus estuarine waters show a constant and around $20 \mathrm{nM}$ copper concentration during the estuarine mixing. Most of this copper is organically complexed by a strong ligand $\left(L_{1}\right)$ with a concentration that varies between 19-55 nM and a log $\mathrm{K}^{\prime}$ between 14.14-15.75. In addition L1/Cu ratios are quite constants and close to 1 all through the estuary, indicating the same source. A second and weakest ligand $\left(L_{2}\right)$ was also detected in these waters in higher concentrations (36-368 nM) but with a lower $\log \mathrm{K}^{\prime}$ that varies between 12.06-13.13. The present work has demonstrated that salt-marsh areas are important and continuous sources of copper complexing ligands to the Tagus estuary. Noticeable, tidal induced transport continuously feed these waters with copper and ligands, mainly with the strongest one. This continuous input, together with the high residence times of this system results in a quite constant concentration along the salinity gradient. This input represents $95 \%$ of the ligand present in the estuary.

Keywords: copper; ligands; speciation; estuary; salt-marsh; Tagus

\section{INTRODUCTION}

Salt-marshes are among the most common and extensive intertidal habitats along temperate coastlines. the colonized sediments (Caçador et al., 1993; Sundby et al., 1998; Caetano et al., 2007). Root-sediment 
interactions appear to contribute to the metal enrichment of colonized sediments and belowground biomass (Caçador et al., 1993) as well as porewaters (Santos-Echeandía et al., 2010).

Not only the concentrations, but also trace metals chemical forms in estuarine water (porewater and water column) may control their bioavailability and toxicity. In the water column, speciation of many biologically active trace metals is controlled by complexation with strong organic ligands (Bruland et al., 1991). Copper (Cu) is probably the most studied metal in terms of organic complexation in seawater and estuarine environments. This is because copper is a micronutrient, but it is also toxic, for example for microalgae, at relatively low concentration levels. In addition, $\mathrm{Cu}$ forms complexes of relatively high stability with various organic ligands. However, no many studies about copper complexation in saltmarsh areas (Mucha et al., 2008) and its influence on the ligand budget of an estuary have been published till these days.

Several sources of organic matter and ligands to estuarine and coastal areas have been pointed out in the last years determining trace metal distribution along the salinity gradient (Laglera and van den Berg, 2003; Santos-Echeandia et al., 2008). In this way, autochthonous organisms are major producers of the ligands that dominate the complexing capacity of open ocean and coastal productive waters (Croot et al., 2000; Gordon et al., 2000). Organisms such as coccolithophores (Leal et al., 1999), cyanobacteria, dinoflagellates (Croot et al., 2000) and heterotrophic bacteria (Gordon et al., 2000) have been observed to excrete strong Cu-complexing ligands, most likely as a defense mechanism against metal toxicity. The input of terrestrial humic substances through riverine waters has also been recognized as an important source of strong ligands to estuarine environments (Kogut and Voelker, 2001; Shank et al., 2004a; Laglera et al., 2009).

Recent studies have shown that estuarine sediments can also act as a significant source of $\mathrm{Cu}$ complexing ligands to the overlying water, which may strongly influence the biogeochemistry and cycling of dissolved Cu by sediment/water exchange (Skrabal et al., 1997, 2000; Shank et al., 2004b, Chapman et al., 2009). This source of organic ligands would be enhanced if sediments are colonized by plants (Mucha et al., 2008). In the last years, several studies conducted in salt marsh areas, have shown that as roots die they supply important quantities of organic matter to the sediment (Caçador et al., 2004; Pereira et al., 2007). In addition, low molecular weight organic acids are exudated by salt-marsh 

high affinity to organic matter.

As tidal water floods the salt marsh, large quantities of organic material, nutrients and trace metals accumulated in the area are exported to the estuary. On a semidiurnal tidal scale, advective fluxes are enhanced in salt marsh sediments (Santos-Echeandía et al., 2010) through a mosaic of small channels in the upper sediments. The relevance of the tidal induced transport on copper and complexing ligands may be crucial to understand the biogeochemical cycles of metals in coastal ecosystems where saltmarshes occupy large extensions.

Thus, the objectives of this work are: a) to measure dissolved copper and complexing ligand concentrations in the Tagus estuarine waters b) to determine dissolved copper and complexing ligand concentrations in the Rosário salt-marsh flooding and porewaters c) to estimate dissolved copper and ligand advective fluxes in the Rosário saltmarsh d) to ascertain the importance of this input over the Tagus estuarine waters.

\section{MATERIAL AND METHODS}

\subsection{Study area}

The $340 \mathrm{~km}^{2}$ of the Tagus estuary represent one of the largest transitional systems in Europe. The estuary is composed by a large shallow inner bay and a deep straight and narrow inlet channel (Fig. 1). This channel reaches a depth of $40 \mathrm{~m}$ and constitutes the deepest part of the estuary. The bay has a complex bottom topography with channels, tidal flats and islands. The deepest channel, with a water depth of 5-10 m, is an extension of the inlet channel. The total amount of water in the estuary is around $1.9 \mathrm{~km}^{3}$. The southern and eastern parts of the bay contain extensive inter-tidal mudflats; the northern part contains tidal flats, islands and several smaller channels. These channels merge upstream to a single narrow channel, marking the entrance of the Tagus River. pronounced dry season/wet season as well as large inter-annual variation. The average annual discharge is $\sim 400 \mathrm{~m}^{3} \mathrm{~s}^{-1}$, but seasonally the average monthly discharge may vary from $1 \mathrm{~m}^{3} \mathrm{~s}^{-1}$ to $>2200 \mathrm{~m}^{3} \mathrm{~s}^{-1}$ (Loureiro, 1979). Consequently, the residence time of freshwater in the estuary is highly variable and 
may range seasonally from 6 to 65 days (Braunschweig et al., 2003). The tides are semi-diurnal, with amplitudes at Lisbon ranging from $\sim 1 \mathrm{~m}$ at neap tide to $\sim 4 \mathrm{~m}$ at spring tide. The tidal effect reaches 80 $\mathrm{km}$ landward of the estuary mouth. Most pollutants are discharged from upper to the lower estuary (Fig. 1). Indeed, apart from being a major harbor, the fishing activities in the estuary are adversely affected by the inflow of effluents from about 3.5 million Greater Lisbon inhabitants, part of them untreated, coupled with industrial (chemicals and petrochemicals) and agricultural (fertilizers and pesticides) contributions.

Almost $40 \%$ of the estuary is composed by inter-tidal mudflats mainly in southern and eastern shores, containing extensive areas of salt marshes colonised mainly by Sarcocornia fruticosa, Sarcocornia perennis, Halimione portulacoides and Spartina maritima occupying an area around $20 \mathrm{~km}^{2}$. The marsh selected for this study (Rosário) is located in the southern shoreline of the estuary (Fig.1). It covers an area of $2 \mathrm{~km}^{2}$ (Crespo, 1993), being characterised by homogeneous stands of S. maritima as a pioneer species in the lower part, pure stands of $H$. portulacoides across the $20-50 \mathrm{~cm}$ elevation transect, and $S$. fruticosa and S. perennis in the higher salt marsh. The marsh is fully inundated twice a day by tidal action (2-4 $\mathrm{m}$ of tidal amplitude) through a highly branched system of channels that cross the elevation transect. The channels have 0.5-1.5 m depth promoting the inundation of the higher marsh even at low amplitude tides.

\subsection{Sampling}

A sampling cruise along the Tagus estuary was conducted on the $5^{\text {th }}$ May 2010. A $93 \mathrm{~m}^{3} \mathrm{~s}^{-1}$ flow was measured during that day what gives a residence time around 62 days for the water in the estuary (Braunschweig et al., 2003). Ten sub-surface water samples (TWB11-TWB410) were collected by hand in $1 \mathrm{~L}$ low density polyethylene (LDPE) bottles from a plastic boat (Fig. 1) during the low tide covering the salinity gradient of the estuary. In addition, flooding water during tidal inundation was sampled in two sites of the Rosário salt marsh (non-vegetated area and S.maritima colonised area and separated by less than $20 \mathrm{~m})$. At low tide, when sediment was exposed to the atmosphere, two sediment cores $(10 \mathrm{~cm}$ long) were collected at each site (vegetated and non-vegetated). The cores were sliced immediately after sampling in two $4 \mathrm{~cm}$ layers, prepared composite samples for each layer of the cores collected at each site, and material stored in acid pre-cleaned HDPE vials avoiding air presence inside. Sampling took 
place in less than $3 \mathrm{~min}$. Core material in the colonized area consisted of dense rooting sediments with no evidence of burrowing worms, crabs or bivalves. When tidal water starts to flood each site, flooding water was collected at each inundation time: 1, 5, 10, 15, 20 and $30 \mathrm{~min}$ for the non-vegetated area and

$1121,5,10,15,20,30,45$ and $85 \mathrm{~min}$ for plant colonized area. Flooding water was sampled $1 \mathrm{~cm}$ above the sediment surface directly into acid pre-cleaned syringes. The water and sediment samples were kept in refrigerated boxes and immediately transported to the laboratory. A more detailed description of these sampling procedures can be found in previous works (Caetano et al., 2007).

\subsection{Sample treatment}

117 Estuarine and flooding water samples were filtered through $0.45 \mu \mathrm{m}$ cellulose membranes placed in previously acid-cleaned filtration units (Nalgene). Filters were frozen and stored at $-20^{\circ} \mathrm{C}$ pending analysis of particulate copper and aluminium. The main reason for measuring particulate aluminium is that it acts as a tracer of lithogenic or terrigenous material (Windom et al., 1989; Pohl et al., 2004) and will be useful for the interpretation of the various sources of material to estuarine waters (i.e. rivers or sediment resuspension) (Mota et al., 2005). Pore waters were separated from the sediment layers by centrifugation at 10,160 rcfxg for $30 \mathrm{~min}$ at +4 ${ }^{\circ} \mathrm{C}$ and filtered through $0.45 \mu \mathrm{m}$ cellulose acetate membranes. Filtration and subsequent manipulation of the samples were carried out in a glove box under argon atmosphere in order to avoid alteration of the initial conditions (Caetano et al., 2007; Santos-Echeandia et al., 2009). A portion of the filtered samples (around $200 \mathrm{~mL}$ ) was frozen for speciation analysis while around $100 \mathrm{~mL}$ were acidified with suprapure $\mathrm{HCl}(\mathrm{pH}<2)$ and stored pending analysis of total dissolved copper.

\subsection{Copper analysis in estuarine water}

\subsubsection{Total dissolved copper concentrations}

131 Copper analyses were carried out using voltammetric equipment (Metrohm 797 VA Computrace) 132 controlled by a computer (PC). The reference electrode was a double junction, $\mathrm{Ag} / \mathrm{AgCl}, \mathrm{KCl}(3 \mathrm{M})$, saturated $\mathrm{AgCl}$, with a salt-bridge filled with $3 \mathrm{M} \mathrm{KCl}$, and the counter electrode was a glassy carbon rod. concentration in the filtered samples was determined using a procedure similar to the one described 

acidification to $\mathrm{pH} 2.2$ by the addition of $10 \mu \mathrm{L} 6 \mathrm{M}$ bidistilled $\mathrm{HCl}$ (AnalR BDH) per $10 \mathrm{~mL}$ of sample in acid-cleaned borosilicate glass tubes. A $10 \mathrm{~mL}$ sample aliquot was pipetted into the voltammetric cell and ammonia (AristarGrade Merck) was used to ascertain the approximate neutralization of the $\mathrm{pH}$; also, HEPES buffer (BDH, final concentration 0.01 M) and Salycildoxime (SA, Sigma, final concentration of $25 \mu \mathrm{M} \mathrm{SA}$ ) were added. The solution was deaerated by purging $(5 \mathrm{~min})$ with nitrogen. The voltammetric parameters were: deposition $60 \mathrm{~s}$ at $-1.1 \mathrm{~V}$ whilst stirring, $8 \mathrm{~s}$ quiescence at $-0.1 \mathrm{~V}$, and a potential scan using the square-wave modulation: $10 \mathrm{~Hz}$, step height $2.5 \mathrm{mV}$, pulse height $25 \mathrm{mV}$, from 0 to $-0.8 \mathrm{~V}$. The sensitivity was calibrated by incorporating standard copper additions (Spectrosol BDH) to each sample. Each sample was analyzed in triplicate. A blank with Milli-Q water $(18.2 \mathrm{M} \Omega . \mathrm{cm})$ was made at intervals of every three samples and its concentration was subtracted in order to eliminate any copper contribution from reagents. Blank concentrations were around $0.27 \pm 0.06 \mathrm{nM}$.

\subsubsection{Copper titrations}

The copper complexing capacity of the waters of the Tagus estuary was determined by competing ligand exchange with adsorptive cathodic stripping voltammetry (CLE-AdCSV) of Cu-salycilaldoxime (SA) complexes according to previous works on copper complexation in estuarine waters (Campos and van den Berg, 1994; Laglera and Van Den Berg, 2003). Briefly, a 170-ml sample previously filtered by $0.45 \mu \mathrm{m}$ was transferred to a polyethylene bottle (Nalgene), and spiked with $\mathrm{HEPES} / \mathrm{NH}_{4} \mathrm{OH}$ buffer (for a concentration of $0.01 \mathrm{M}$ ) and SA (mix concentration of 5 or $10 \mu \mathrm{M}$ ). After stirring, $10 \mathrm{~mL}$ aliquots were pipetted into 15 polystyrene vials ( $30 \mathrm{~mL}$ Bibby, Sterilin) that were previously spiked with copper to provide increasing concentrations in the range of $0-700 \mathrm{nM}$ (actual range depending on the initial copper concentration and the ligand concentration to be determined). Prior to the first titration, the tubes were conditioned twice overnight with seawater containing the same range of copper concentrations in order to avoid copper loss in the tube walls. After that, aliquots of each sample were left to equilibrate overnight at room temperature due to the slow kinetics of the ligands and copper reactions (Campos and van den Berg, 1994). The equilibrium concentration of Cu-SA complexes was determined using the following parameters: adsorption potential of- $0.15 \mathrm{~V}$, deposition time of $60 \mathrm{~s}, 8 \mathrm{~s}$ 

and pulse height of $25 \mathrm{mV}$.

\subsubsection{Evaluation of complexing capacities and conditional stability constants}

167 Changes in the ratio between the concentrations of CuSA (labile to AdCSV) and CuL in the different aliquots permit the determination of the copper complexing capacity of the ligands present in solution $\left(\mathrm{C}_{\mathrm{L}}\right)$ and their conditional stability constant to bind copper $\left(\mathrm{K}_{\mathrm{CuL}}^{\prime}\right)$. A more detailed explanation can be found elsewhere (Ruzic, 1982; van den Berg, 1982). The relationship between the different copper fractions is described by the following transformation of the Langmuir isotherm:

$$
[\mathrm{Cu}]_{\mathrm{TOT}}=\Sigma\left(\mathrm{C}_{\mathrm{Li}}[\mathrm{Cu}]_{\mathrm{lab}} / \mathrm{K}_{\mathrm{CuLi \alpha}}^{\prime}+[\mathrm{Cu}]_{\mathrm{lab}}\right)+[\mathrm{Cu}]_{\mathrm{lab}}
$$

$L_{i}$ represents the variability of the nature of the different natural ligands. Those ligands are differentiated according to the stability of their complexes with copper. $\alpha^{\prime}$ is the $\alpha$-coefficient of $\mathrm{Cu}^{2+}$ with inorganic ligands and SA. $[\mathrm{Cu}]_{\text {TOт }}$ and $[\mathrm{Cu}]_{\text {lab }}$ are respectively the total and labile copper concentrations related by:

$$
[\mathrm{Cu}]_{\mathrm{ab}}=\mathrm{i}_{\mathrm{p}} / \mathrm{S}
$$

Where $i_{p}$ is the voltammetric signal obtained from the reduction of the CuSA complexes adsorbed on the HMDE electrode and $\mathrm{S}$ is the ratio signal/concentration or sensitivity. $\mathrm{S}$ can be estimated from the slope of the last few points of the titration $\left(\mathrm{S}^{\mathrm{INT}}\right)$ if the titration has been extended to copper concentrations enough to complete the saturation of the natural ligands.

As indicated in the previous section, samples were analyzed using two different SA concentrations (5 and $10 \mu \mathrm{M})$. Higher SA concentrations increase the competing ability of SA. In the presence of complex mixes of ligands characterized by the formation of complexes with copper in a wide range of stability constants, the effect of increasing the SA concentration is both, an overcompetition of those ligands of low affinity for copper and the equilibration of SA with ligands of very high stability constant. Therefore, in heterogeneous matrices, the shift of the SA concentration resolves a different fraction of ligands, 
fraction that is defined as detection window. This is an important tool to estimate the heterogeniety of the pool of copper ligands in the sample.

Values for the stability constants of the complexes CuSA and $\mathrm{Cu}(\mathrm{SA})_{2}$ are necessary in order to obtain the value of $\alpha^{\prime}$ at each salinity. Both stability constant were calculated using relationships obtained in a previous work (Campos and van den Berg, 1994):

$$
\begin{aligned}
& \log K_{\text {CUSA }}=(10.12 \pm 0.03)-(0.37 \pm 0.02) \log \text { salinity } \\
& \log \beta_{C u(S A) 2}^{\prime}=(15.78 \pm 0.08)-(0.53 \pm 0.07) \log \text { salinity. }
\end{aligned}
$$

A plot of $\left[\mathrm{Cu}_{\mathrm{lab}}\right]$ vs the ratio $[\mathrm{Cu}]_{\mathrm{lab}} /[\mathrm{CuL}]$ is the most used procedure to solve $\mathrm{C}_{\mathrm{L}}$ and $\mathrm{K}^{\prime}{ }_{\mathrm{CuL}}$ from the slope and the $\mathrm{Y}$-axis value respectively. When only one ligand is present, the data follow a straight line but if more than one type of ligands are present, the plot takes a curved shape. In this case $\mathrm{C}_{\mathrm{L}}$ and $\mathrm{K}_{\text {CuL }}$ can be calculated with accuracy for a maximum of two types of ligands.

The estimation of $\mathrm{C}_{\mathrm{L} 1}, \mathrm{~K}_{\mathrm{CuL} 1}^{\prime}, \mathrm{C}_{\mathrm{L} 2}$ and $\mathrm{K}_{\mathrm{CuL2}}^{\prime}$ requires either an iterative refine procedure (Laglera-Baquer et al., 2001; van den Berg, 1982) or a nonlinear fitting (Gerringa et al., 1995). In the first case the solutions for $C_{L 1}$ and $K^{\prime}{ }_{C u L 1}$ are refined with estimations of $C_{L 2}$ and $K^{\prime}{ }_{C u L 2}$ from different linear sections of the plot until a convergent solution is obtained.

Complexing capacities, conditional stability constants and S can also be obtained fitting non-linearly the substitution of $\mathrm{Eq}(3)$ in $\mathrm{Eq}(1)$. Non-linear fitting prevents the uncertainty caused by the arbitrary necessity to split the titration data in two that iterative linear fitting requires.

In this work, we have used the fitting tool of a popular computer program, SigmaPlot (C) Systat Software, Inc) to fit 3, 4 or 5 parameters. The program uses a Levenberg-Marquardt fitting algorithm. We first solved the titration data sets for the hypothesis of a single ligand model using non-linear fitting incorporating $S$ as a parameter to $C_{L}$ and $K$. For this purpose, a new equation was incorporated to the Regression Wizard of the software under the "User-Defined" category. The Code fed to the Regression Wizard is presented in Table S1.

Then, we prepared a new Equation for the case of two types of ligands, i.e. 5 parameters $\left(\mathrm{C}_{\mathrm{L} 1}, \mathrm{~K}_{\mathrm{CuL1}}^{\prime}, \mathrm{C}_{\mathrm{L} 2}\right.$ and $\mathrm{K}_{\text {CuL2 }}^{\prime}$ and S) but the program struggled to offer realistic values in the form of very high $\mathrm{S}$ and $\mathrm{K}_{\text {CuL1 }}^{\prime}$ values. Removal of $S$ from the list of parameters and use of $S^{\text {INT }}$ did not solve problems with $K^{\prime}{ }_{\text {CuL1 }}$ for 
217 some titrations. In those cases, $\mathrm{K}_{\text {Cul1 }}$ was obtained from the iterative linear routine and its value fixed in

218 the constrains section of the code (Table S1) during the non-linear fitting of the rest of the complexing 219 parameters.

\subsubsection{Particulate copper and aluminum}

221 In order to determine the amount of labile copper, filters obtained from filtered water were subject to digestion overnight with $0.1 \mathrm{M}$ acetic acid in Teflon ${ }^{\circledR}$ vials (Savillex) at ambient temperature following the first step of the BCR extraction procedure (European Community Bureau of Reference; Quevauviller et al., 1997). The digest was then syringed-filtered $(0.45 \mu \mathrm{m})$ using a Swinnex filtration unit and stored pending analysis; filters containing the remnant particles were microwave digested using a mixture of $\mathrm{HF}$ and $\mathrm{HNO}_{3}(1: 3)$ in order to analyze the total fraction (Biscombe, 2004).

Labile copper determination was carried out by means of cathodic stripping voltammetry as explained before (Campos and van den Berg, 1994) while total particulate copper and aluminum determination was carried out with the standard additions method. Concentrations of Al and Cu were determined using a quadrupole ICP-MS (Thermo Elemental, X-Series) equipped with a Peltier Impact bead spray chamber and a concentric Meinhard nebulizer. Coefficients of variation for metal counts $(n=5)$ varied between 0.5 and $2 \%$. The precision and accuracy of each metal concentration measurements, determined through repeated analysis of certified reference material (PACS2), using Indium as internal standard, were 1-4\% and 2-5\%, respectively (data not shown). Procedural blanks always accounted for less than $1 \%$ of the total metal concentrations in samples.

\subsection{Estimation of sediment-water interchange: tidal induced fluxes}

As water floods over inter-tidal sediments the pore water solutes tend to be exported by advection and/or exchanged between mixing top sediments and tidal water. The associated pressure difference and tidal water movement are the driven mechanism for this transport. By using the temporal variation of copper and ligand concentrations in the flooding water the tidal induce transport $(T)$ to the water column is calculated using the following expression (Caetano et al., 2007).

$$
T=\Sigma\left[\left(C_{t+1}-C_{t}\right) /\left(2-C_{i}\right)\right]\left(h_{t+1}-h_{t}\right)
$$


where $C_{t+1}$ and $C_{t}$ are solute (copper and ligand) concentrations in the flooding water at times $t+1$ and $t$,

$244 C_{i}$ is the residual concentration (lowest value obtained for the flooding water) and ht and $h_{t+1}$ are the water depth at the same times. It was observed that water depth during the field measurements increased on the average 0.5 and $0.8 \mathrm{~cm}$ per minute of inundation in S. maritima and non-vegetated areas, respectively. The tidal induced transport of trace metals is calculated for the first 85 and 30 min of inundation, respectively. Since inter-tidal sediments are inundated twice a day, the tidal induce transport $(T)$ was multiplied by a factor of two to present values on a daily basis.

The statistical analyses were performed using STATISTICA 6 (Statsoft).

\section{RESULTS}

\subsection{Determination of the complexing parameters and the sensitivity by non-linear fitting}

Table 1 shows the complexing parameters found for the estuarine water samples according to one and two ligands models. Table 2 shows those parameters for flooding waters and interstitial waters extracted from cores. For the one ligand model, $\mathrm{S}$ was added to the fitting procedure according to the

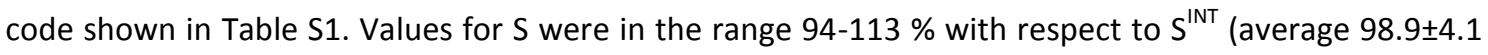
\%) indicating that any bias due to undersaturation of the ligands present in the sample caused by a too small copper concentration at the end of the titration was masked by the analytical error. For the sample collected at station $11, \mathrm{~S}$ was fitted at a very low value $90 \%$ of $S^{\mathrm{INT}}$ and the complexing parameters were recalculated using $\mathrm{S}^{\mathrm{INT}}$.

For the two ligands model, this approach was not possible as explained above. For some titration sets, $\mathrm{S}$ was estimated to be $103-114 \%$ of $S^{\text {INT }}$ but for many others this correction reached as much as $170 \%$ which could be discarded simply by visual inspection. Values in Table 2 were obtained using $s^{\text {INT }}$. When the estimation of $K_{\text {Cul1 }}^{\prime}$ produced a value over 20 , the titration data set was solved by iterative linear fitting (Laglera-Baquer et al., 2001; Laglera and Van Den Berg, 2003) and the value of $K_{\text {CuL1 }}^{\prime}$ fixed on the constrains section of the code. This led to a 3 parameters non-linear fitting. An extensive description of separate work (Laglera et al., 2012). 
271 Dissolved copper concentrations along the salinity gradient in the Tagus estuary are plotted in Fig. 2 a.

272 With the exception of the station located upstream in the river (26.4 nM), values were quite constants

273 and around $20 \mathrm{nM}$ all over the estuary. The ligand concentration ( $\mathrm{L}$; Fig. 2a), for the $5 \mu \mathrm{M}$ SA detection

274 window, showed higher values in riverine samples (399 nM) decreasing to 320-340 nM in the first 3

275 units of salinity. A new decay is found from salinity 5 to 25 (to $46 \mathrm{nM}$ ). This decreasing trend from fresh

276 to marine waters has been observed before in other estuarine systems (Laglera et al., 2003; Plavsic et

277 al., 2009). The conditional stability constant for these ligands (log K') ranges between 12.20 and 13.26

278 (Table 1), and it presents a bowl-shape distribution along the salinity gradient, with lower values in the 279 mid-estuary and maxima at marine (13.26) and riverine (13.11) end-members.

280 By fitting data to two types of ligands, a strong $\left(L_{1}\right)$ and a weak $\left(L_{2}\right)$ one can be observed in the Tagus 281 estuary waters (Fig. 2a). Ligand $L_{1}$ varied between 14 and $55 \mathrm{nM}$ being the highest concentration found in the two most riverine stations. Values decreased sharply to $15 \mathrm{nM}$ at salinity 3 remaining almost constant until the marine end member (salinity 25). Otherwise, $L_{2}$ concentrations vary between 36 and $368 \mathrm{nM}$ with a conservative distribution between salinities 5 and 25, but with lower values than expected for an ideal dilution line between salinities 0 and 5 . The conditional stability constants for these ligands range between 14.10 and 15.75 for $L_{1}$ and between 12.06 and 13.13 for $L_{2}$ (Table1). The distribution along the salinity gradient is different among them; while $\log K_{1}{ }^{\prime}$ shows a saw tooth tendency with higher values in the riverine end-member, $\log K_{2}^{\prime}$ distribution is comparable to log $K^{\prime}$, with the lowest values in the mid estuary and increasing towards the river (13.13) or the sea (12.42) end members.

In order to detect stronger copper complexing ligands and check for homogeneity/heterogeneity of them in the estuary (van den Berg and Donat, 1992; Buck and Bruland., 2005; Santos-Echeandia et al., 2008), a detection window of $10 \mu \mathrm{M}$ SA has been applied to some of the samples. Samples, fitted to one ligand are plotted in Fig. 2b. Ligand concentration increases between salinity 0 and 5 (from 121 to 142 $\mathrm{nM}$ ) and progressively decreases to $30 \mathrm{nM}$ at salinity 25 with a quite linear trend. The conditional stability constant (log $\left.K^{\prime}\right)$ presented, again, lower values at mid salinities (13.11) increasing towards the riverine (14.52) and marine (13.76-14.15) end members (Table 1) as observed for the lower detection 
window $\left(5 \mu \mathrm{M}\right.$ SA). By fitting data to two types of ligands, the strongest one $\left(\mathrm{L}_{1}\right)$ concentrations ranged between 15 and $28 \mathrm{nM}$ (Fig. 2b) with a quite irregular distribution. On the contrary, the weakest ligand of this detection window $\left(L_{2}\right)$ shows a similar trend to $L$, with an initial increased from 145 to $174 \mathrm{nM}$ decreasing progressively afterwards to $22 \mathrm{nM}$ at salinity 25 . The conditional stability constants, both log $K_{1}^{\prime}$ and $\log K_{2}^{\prime}$ present higher values at low salinities (16.84 for $K_{1}$ and 13.87 for $K_{2}$ ) that sharply decreased at salinity 5 reaching 15.02 for $\log \mathrm{K}_{1}{ }^{\prime}$ and 12.76 for $\log \mathrm{K}_{2}{ }^{\prime}$ remaining relatively constant towards the marine end-member (Table 1).

3.3. Suspended Particulate Matter, particulate total and labile copper and aluminium concentrations in the Tagus estuary Suspended particulate matter values oscillate between 4.8-14.7 $\mathrm{mg} \mathrm{L}^{-1}$ in the estuary with an irregular distribution (Fig. S1a). The highest values where found at salinities 10-15 and the lowest between salinities 19-23. Particulate copper concentrations varied between 0.78 and $14.8 \mathrm{nM}$ (Fig. S1b). The highest levels were found at mid-salinities (5-15 ups) while the lowest values measured at both endmembers. The labile copper in the particulate matter accounts only for the $0.05-0.45 \%$ of the total copper but it is noticeable that the lability was higher for the lowest salinities (Fig. S1c). Particulate aluminum concentrations ranged between 272 and $4930 \mathrm{nM}$ with a similar distribution to particulate copper.

\subsection{Dissolved copper and its organic speciation in the Rosario Saltmarsh}

\subsubsection{Flooding waters}

317 Dissolved copper concentrations in the flooding water in the two sites of the salt marsh (non-vegetated

318 and plant colonized areas) are plotted in Fig. 3a. Copper levels in the non-vegetated zone increase 1 minute after arriving of tide water from 18.3 to $28.5 \mathrm{nM}$. In the following 5 minutes, levels decreased reaching $20.6 \mathrm{nM}$ and remaining quite constant until 30 minutes after tidal inundation started, with the exception of minute 15 when a less pronounced increase $(27.0 \mathrm{nM})$ was observed (Fig. 3a). In a similar way, dissolved copper levels increased in the colonized area 1 minute after the flood started reaching higher values (32.5 nM) than in the non-vegetated area. Afterwards, concentrations decreased to 17.7 $\mathrm{nM}$ and varied irregularly between 13.6 and $22.1 \mathrm{nM}$ during the next 80 minutes of inundation. 
The time course evolution of ligand concentration in the flooding waters is also plotted in Fig. 3a. A net increase of its concentration (initial levels of $46 \mathrm{nM}$ ) was observed in both sampling areas but reaching higher concentrations in the plant colonized (291 nM) than in the non-vegetated area ( $85 \mathrm{nM})$ during the first minute of inundation. Afterwards levels in plant colonized sediments decreased sharply while in non-vegetated area values diminished progressively reaching, at both areas similar values to those found before inundation started. The conditional stability constants of ligand showed higher values in the non-vegetated (13.73-14.04) than in the plant colonized area (13.11-13.89) (Table 2). The significance for statistical analyses was $p<0.05$.

In addition, the time course evolution of log $\mathrm{K}^{\prime}$ values during the tidal inundation were different among the two sites: while an increase of log $\mathrm{K}^{\prime}$ was found one minute after the inundation started in the nonvegetated area, a progressive increase of log $\mathrm{K}^{\prime}$ with time was observed in the vegetated area during the first 10 minutes.

The strongest ligand $\left(\mathrm{L}_{1}\right)$ concentrations vary between 46 and $61 \mathrm{nM}$ in the non-vegetated area without a trend all over the time (Fig. 3b). Nevertheless, $\mathrm{L}_{1}$ concentrations in the colonized area are more variable and ranged between 28 and $95 \mathrm{nM}$. The conditional stability constant of this ligand varied between 14.12 and 14.79 in the non-vegetated area while in the colonized area a variation between 13.61 and 14.83 was found (Table 2). The weakest ligand concentrations were higher and varied between 60 and $107 \mathrm{nM}$ for the non-vegetated area and from 5.5 to $258 \mathrm{nM}$ for the colonized area (Fig. $3 b)$. It is noticeable the net increase in the colonized area in the first minutes of inundation that is not observed in the non-vegetated area. Finally, conditionals stability constant for this weakest ligand oscillate between 11.95-12.26 nM in the non-vegetated area and 11.87-13.05 in the colonized area (Table 2).

Strongest ligands have been detected in the flooding waters moving the detection window to $10 \mu \mathrm{M}$ SA. Ligand concentration were lower (61-87 nM) in the non-vegetated area than in the colonized site (107$137 \mathrm{nM}$ ) during the first 5 minutes of inundation (Fig. 3c). An increase was found in the first minute comparing to the estuarine waters in the vicinity of the salt-marsh and concentrations slightly decrease after 5 minutes. The respective conditional stability constants were similar in the non-vegetated area (14.39-14.48 nM) and in the plant-colonized area (14.32-14.47 nM) (Table 2). 

and $82 \mathrm{nM}$ for $L_{1}$ and from 59 to $138 \mathrm{nM}$ for $L_{2}$ with a similar trend to the unique ligand (L). However, $L_{1}$ levels do not decrease after 5 minutes but continue to increase (Fig. 3c). Conditional stability constants ranged in the following intervals: $14.63-15.69$ for $L_{1}$; and 12.84-13.44 for $L_{2}$ (Table 2).

\subsubsection{Porewaters.}

Dissolved copper and ligand concentrations and their conditional stability constants in the porewaters of the salt-marsh are shown in Table 3. Levels of dissolved copper in the non-vegetated area ranged from 45.3 to $53.9 \mathrm{nM}$ with higher values in the upper layer than in the deeper one. However, higher ligand concentrations were found in deeper porewaters (321 nM) than in surface ones (245 nM). The conditional stability constants for these ligands varied between 13.24 for the deeper layer and 13.58 for the upper one. Levels of the stronger ligand $\left(L_{1}\right)$ ranged from 77 to $184 \mathrm{nM}$ with higher values in the upper layer. Nevertheless, the conditional stability constant was higher (14.77) in the deeper layer than in the upper one (13.70). Concentrations of $L_{2}$ varied between 70 and $287 \mathrm{nM}$ with increased values in the deeper layer. The conditional stability constants of this weakest ligand were 12.68 for the deeper layer and 13.09 for the upper one.

Higher dissolved copper concentrations in pore waters (71-142 nM) were found in the plant colonized area (Table 3). Ligand concentrations vary between $767 \mathrm{nM}$ in the deeper layer and $831 \mathrm{nM}$ in the upper one. Conditional stability constant for this ligand showed higher values in the upper layer. The stronger ligand, $L_{1}$, levels varied between 115 and $203 \mathrm{nM}$ with higher values in the upper layer and their conditional stability constants were 15.17 for the upper layer and 14.66 for the deeper one. Concentrations of $L_{2}$ were quite similar among layers (666 and $699 \mathrm{nM}$ ) as the conditional stability constants (13.09 and 12.82).

Strongest ligands in pore waters were found by applying a higher detection window (10 $\mu \mathrm{M})$ (Table 3). Ligand concentration in the non-colonized area was $230 \mathrm{nM}$ with a conditional stability constant of 14.28. A strong ligand with a $\log \mathrm{K}_{1}{ }^{\prime}$ of 15.25 and a concentration of $67 \mathrm{nM}$ and a weak ligand with a log $\mathrm{K}_{2}{ }^{\prime}$ of 13.85 and a concentration of $182 \mathrm{nM}$ result from the data fitting to two types of ligands. As found with the $5 \mu \mathrm{M}$ SA detection window, higher values were observed in the vegetated area at $10 \mu \mathrm{M}$ detection window. A ligand concentration of $419 \mathrm{nM}$ with a log $\mathrm{K}^{\prime}$ of 13.95 was registered. In the data 
381 fitting to two types of ligands, a strong ligand concentration of $148 \mathrm{nM}$ with a log $\mathrm{K}_{1}^{\prime}$ of 17.56 was

382 recorded, while the weakest ligand showed a concentration of 846 with a log $K_{2}^{\prime}$ of 13.51.

383

384

385

386

387

388

389

390

391

392

393

394

395

396

397

398

399

400

401

402

403

404

405

406

407

\subsection{Tidal induced transport of copper and organic ligands in the Rosario Saltmarsh}

An estimation of the tidal induced transport of dissolved copper and ligands is shown in Table 4. A flux of $1.23 \mu \mathrm{mol} \mathrm{m} \mathrm{m}^{-1}$ of dissolved copper escapes from the sediment to the overlying waters in the nonvegetated area, while the ligand transport was $3.25 \mu \mathrm{mol} \mathrm{m} \mathrm{m}^{-1}$. If the two ligand case is considered, an export of $2.16 \mu \mathrm{mol} \mathrm{m} \mathrm{m}^{-2}$ of the strongest ligand and $2.31 \mu \mathrm{mol} \mathrm{m} \mathrm{m}^{-1}$ of the weakest one was estimated. As expected from the results shown in previous sections calculated transports are higher in the plant colonized area, where a $2.43 \mu \mathrm{mol} \mathrm{m} \mathrm{d}^{-1}$ flux of dissolved copper is estimated. The ligand flux $\left(48.2 \mu \mathrm{mol} \mathrm{m} \mathrm{d}^{-1}\right)$ was around fifteen times higher than in the non-vegetated area. Increased transport of both strong and weak ligand to the water column was also found with $11.5 \mu \mathrm{mol} \mathrm{m} \mathrm{d}^{-1}$ for $\mathrm{L}_{1}$ and $64.7 \mu \mathrm{mol} \mathrm{m} \mathrm{d}^{-1}$ for $\mathrm{L}_{2}$.

The tidal induced transport of ligands detected by the $10 \mu \mathrm{M}$ SA detection window was similar in the non-vegetated area and lower in the colonized area. In this way, $4.25 \mu \mathrm{mol} \mathrm{m} \mathrm{m}^{-1}$ of ligands were exported in the non-colonized area while $6.87 \mu \mathrm{mol} \mathrm{m} \mathrm{m}^{-2} \mathrm{~d}^{-1}$ were exported in the plant colonized area. For the two ligand case, $3.80 \mu \mathrm{mol} \mathrm{m} \mathrm{d}^{-1}$ of the strongest ligand and $5.77 \mu \mathrm{mol} \mathrm{m} \mathrm{d}^{-1}$ of the weakest one were estimated.

\section{DISCUSSION}

\subsection{Copper and organic ligands behavior during the estuarine mixing}

Dissolved copper and complexing ligand behavior in the Tagus estuary can be clearly divided in two distinct chemical areas. The edge is marked by the salinity 5.6 sample. In the low salinity stretch, although dissolved copper values were only higher in the most riverine sample, the strong ligand values $\left(L_{1}\right)$ were higher than in the rest of the estuary. As a consequence the $L_{1} / C u$ ratio is relatively constant and around 1 . The only exceptions are the two most riverine stations (Fig. S2) where an excess of $L_{1}$, which may derived from the river end member was detected. This ratio is linear and progressively decreases with the increasing salinity if total ligand concentration is considered (Fig. S2). Moreover, the weakest ligand $\left(L_{2}\right)$ also showed a different behavior in this zone of the estuary but with lower levels 
than expected if the trend marked by the seven most saline stations is extended to the freshwater endmember.

The mixing of freshwater with the marine water dilutes $L_{1}$ ligand within the estuarine area. The long residence times (Braunschweig et al., 2003), confirmed by uniform suspended particulate matter content in a wide salinity range (Fig. S1a), allow the homogenization of the water body justifying the constancy of copper and strong ligand levels in the 6-25 salinity range. This pattern suggest that the tidal effect superimposes the river flow and no losses of copper or strong ligands occured during the estuarine mixing. Similar findings have been observed in the Scheldt estuary by Laglera and van den Berg (2003). A continuous lateral input, as detected in the Vigo Ria (Santos-Echeandía et al., 2008), in the Tagus estuary may also explain the constant values all over the salinity gradient. In addition, this area shows constant and close to the unit $\mathrm{L}_{1} / \mathrm{Cu}$ ratios in a wide salinity range (Fig. S2). This means that copper and $L_{1}$ levels are similar probably because their source is the same. There is no evidence of copper transfer from the dissolved to the particulate fraction since values were quite low all through the estuary (Fig. S1b). However, $\mathrm{L}_{2}$ experiments a progressive decrease in their levels towards the outer part of the estuary and no remarkable inputs of $L_{2}$ are observed at mid-high salinities as observed for $L_{1}$. It can be assumed that the river is not the major source of this weak ligand, but its origin is somewhere in between salinities $0-6$, where although the mixing with seawater, its concentration remains constant or even increases. This increase is consistent with the trend observed at both detection windows for the weakest ligand (Fig. 2). The higher particulate aluminum concentrations at salinities 6-10 (Fig. S1c) and SPM at salinity 10 could reflect the maximum turbidity zone in this salinity gradient and at spring tides the bottom particle resuspension in this area may explain the release of the weakest ligand from the sediments (Shank et al., 2004; Santos-Echeandia et al., 2008). If copper variability during the estuarine mixing is associated to $L_{1}, L$ behavior is ruled by $L_{2}$. This fact is supported by the spatial distribution of log $\mathrm{K}_{2}^{\prime}$, which is quite similar to $\log \mathrm{K}^{\prime}$ (Table 1 ) at both detection windows $(5 \mu \mathrm{M}$ y $10 \mu \mathrm{M})$. of the stronger ligand $\left(L_{1}\right)$ was homogeneous, mainly at high salinities, because the log $K_{1,5 \mu \mathrm{MSA}}^{\prime}$ and log $\mathrm{K}_{1,10 \mu \mathrm{MSA}}^{\prime}$ were similar (Table 1 ) and, in general, their ratio was close to 1 (Fig.S3a). Moreover, ratios between $L_{1}$ measured at the low detection window and the $L_{1}$ observed at the high detection window 
437 and a shift to the higher detection window induces the decrease of the ligand concentrations. Thus, the ratio between $L_{2}$ measured at low detection window and at high detection window is around 2

$439(2.09 \pm 0.48)$ (Fig. S3b). An increase of the log $\mathrm{K}^{\prime}$ values is also observed when moving the detection window to $10 \mu \mathrm{M}$ SA. As a consequence the ratios between log K'at high and low detection windows are always well below 1 all over the salinity gradient (Fig. S3a).

\subsection{Saltmarsh inputs of copper and complexing ligands to the estuary} to estuarine waters. Mucha et al. (2008) demonstrated that salt-marsh plants are able to produce relatively high amounts of strong $\mathrm{Cu}$-complexing ligands in their root system and the present study evidenced that these complexes are exported to estuarine waters through tidal induced transport (Table 4).

The constant dissolved copper and $L_{1}$ concentrations in a wide salinity gradient (6-25) is presumably explained by the lateral input from the marsh areas along the gradient coupled with high residence time of water in the estuary. Previous studies have showed that copper levels in the adjacent area to the Tagus ( $\mathrm{S} \geq 30$ ) varied between 1.6 and 14.6, well below the values found at salinity 25 (Cotté-Krieff et al.,

452 2000; Santos-Echeandia et al., 2012). The correlation between $\mathrm{Cu}$ and $\mathrm{L}_{1}(r=0.67, \mathrm{p}<0.05)$ in the Tagus estuarine waters suggest that the source of copper and ligands at mid-salinities is diluted at high salinities. The inexistence of marshes downstream the inlet that connects the estuary to the sea reinforces the hypothesis that salt marshes are the main source of copper and complexing ligands. Moreover, the conditional stability constants for $L_{1}$ in the waters exported from the salt-marsh $(14.34 \pm 0.27$ for the non-colonized area and $14.17 \pm 0.41$ for the vegetated area) are comparable to the ones present in the estuary $(14.38 \pm 0.37)$. for the non-colonized area and $12.29 \pm 0.46$ for the vegetated area) are similar to those present in the estuary, the input through tidal cycles is not reflected in the estuarine distribution of the weak ligand. As

462 shown before, $L_{2}$ concentrations decrease towards higher salinities. A photo-degradation process during 
464

465

466

467

468

469

470

471

472

473

474

475

476

477

478

479

480

481

482

483

484

485

486

487

488

489

490

$\mathrm{mg} \mathrm{L}^{-1}$ against 22-99 $\mathrm{mg} \mathrm{L}^{-1}$ for the Scheldt estuary, Zwolsman and van Eck., 1999) is a possible explanation. The high residence time of the waters in the Tagus estuary would favor this degradation as shown in the Scheldt estuary (Laglera and van den Berg., 2006). According to these authors $L_{2}$ is more susceptible to photo-degradation than $L_{1}$, as the former is stabilized by its complexation with copper. In addition, due to the heterogeneous distribution of this ligand, it is possible that several sources (i.e. harbor, untreated effluents) contribute to the pool of weak ligands.

Considering the water volume of the Tagus estuary $\left(1.9 \times 10^{9} \mathrm{~m}^{3}\right)$, the residence time during the sampling conditions (60 days), the area covered by the intertidal non-vegetated zones $\left(128 \mathrm{~km}^{2}\right)$ and salt marshes $\left(20 \mathrm{~km}^{2}\right)$ and the tidal induce transport of copper and ligands from the sediment to the water column in the Rosário salt-marsh (Table 4), a contribution of around $7 \mathrm{nM}$ of copper, $16 \mathrm{nM}$ of $\mathrm{L}_{1}$ and $52 \mathrm{nM}$ of $\mathrm{L}_{2}$ to the Tagus estuarine waters has been estimated. This account for $35 \%$ of $\mathrm{Cu}, 94 \%$ of $\mathrm{L}_{1}$ and $45 \%$ of $\mathrm{L}_{2}$ present in the estuary $(S \geq 6)$.

This continuous input of copper complexing ligands is beneficial for the health of the estuary. Several inputs of copper coming from a variety of sources, especially in such an industrialized and populated area as it is the Tagus estuary can be neutralized by its binding to natural ligands. This would decrease its toxicity to living organisms when an extra input of copper occurs (Louis et al., 2009).

\section{CONCLUSIONS}

Tagus estuarine waters show a relatively constant copper concentration during the estuarine mixing. Most of this copper is organically complexed by a strong ligand $\left(L_{1}\right)$ all through the estuary. A second and weakest ligand $\left(\mathrm{L}_{2}\right)$ was also detected in these waters in higher concentrations. Salt-marsh areas are the major sources of copper complexing ligands to the Tagus estuary. Noticeable, tidal induced transport continuously feed estuarine waters with copper and ligands, mainly with the strongest one. Its input can represent $95 \%$ of the ligand present in the estuary. Salt-marsh input of copper complexing ligands determines copper distribution along the salinity gradient of the Tagus estuary.

Although future research should be performed to compare the importance of this source of ligands with other sources like urban effluents, rivers or benthic inputs, the present work has demonstrated that salt marsh areas are the main inputs of copper complexing ligands to the Tagus estuary. 

and remediation in estuarine and coastal areas. Furthermore, one may speculate that inundation of coastal areas associated with the climatic changes, either to increase of water levels or floods will result in additional fluxes of trace elements and copper complexing ligands from inter-tidal areas to estuarine and coastal waters. The relevance of the tidal induced transport on copper and complexing ligands coming from salt marsh areas may be crucial to understand the biogeochemical cycles of metals in coastal ecosystems all over the world where salt-marshes occupy large extensions.

Aknowledgements. The authors would like to thank Vasco, Rute and Antonio for their kind sampling cooperation during the sampling campaign. The C.S.I.C., under the program JAE-Doc (Junta para la post-doctoral contract to J. Santos-Echeandía.

\section{REFERENCES}

- Biscombe., 2004. Factors influencing the seawater solubility of aerosol associated trace metals. PhD Thesis. University of Plymouth.

- Braunschweig, F., Martins, F., Chambel, P., Neves, R., 2003. A methodology to estimate renewal time scales in estuaries: the Tagus Estuary case. Ocean Dynamics 53, 137-145.

- Bruland, K.W., Donat, J.R., Hutchins, D.A., 1991. Interactive influences of bioactive trace metals on biological production in oceanic waters. Limnology and Oceanography 36, 1555-1577. analytical windows. Marine Chemistry 96, 185-198.

512 - Caçador, I., Costa, A., Vale, C., 2004. Carbon Storage in Tagus Salt Marsh Sediments. Water Air Soil Pollution: Focus 4, 701-714.

514 - Caçador, I., Vale, C., Catarino, F., 1993. In: Vernet, J.-P. (Ed.), Environmental contamination. Studies in Environmental Sciencevol. 55. Elsevier, Amsterdam, pp. 355-365. 

content and stable isotopic signature Science of the Total Environment 380, 84-92. water by cathodic stripping voltammetry and ligand competition with salicylaldoxime Analytica Chimica Acta 284, 481-496. complexing ligands and thiol compounds in shallow lagoon waters. Marine Environmental Research 67, 17-24.

524 - Cotté-Krieff, M.H., Guieu, C., Thomas, A.J., Martin, J.M., 2000. Sources of $\mathrm{Cd}, \mathrm{Cu}, \mathrm{Ni}$ and $\mathrm{Zn}$ in Portuguese coastal waters. Marine Chemistry 71 (3-4), 199-214.

- Crespo, R., 1993. Cartografia do habitat potencial de passeriformes no Estuário do Tejo por processamento digital de imagem. Degree Thesis. Faculdade de Ciências - Universidade de Lisboa, Portugal, pp. 124.

- Croot, P.L., Moffet, J.W., Brand, L.E., 2000. Production of extracellular Cu complexing ligands by eucaryotic phytoplankton in response to Cu stress. Limnology and Oceanography 45, 619-627.

531 - Gerringa, L.J., Herman, P.M., Poortvliet, T.C., 1995. Comparison of the linear Van den Berg/Ruzic transformation and a non-linear fit of the Langmuir isotherm applied to $\mathrm{Cu}$ speciation data in the estuarine environment. Marine Chemistry 48, 131-142. ligands in cultures of marine bacteria and estuarine water. Marine Chemistry 70, 149-160. seawater. Environmental Science and Technology 35, 1149-1156. 

waters. Marine Chemistry 82 (1-2), 71-89. ligands in estuarine waters. Marine Chemistry 101 (1-2), 130-140. substances in seawater. Limnology and oceanography 54, 610-619. fitting for the estimation of complexing parameters from metal titrations of estuarine samples. Analytica Chimica Acta, submitted. ligands similar to thiols by Emiliania huxleyi in seawater cultures. Limnology and Oceanography $44,1750-1762$. equilibrium studies of copper-dissolved organic matter complexation in water column of the stratified Krka River estuary (Croatia). Marine Chemistry 114, 110-119. Servicio Hidraulico (DGRAH), Lisbon (1979). in the Tagus Estuary. Water Research 39, 1451-1460.

559 - Mucha, A.P., Almeida, C.M.R., Bordalo, A.A., Vasconcelos, M.T.S.D., 2010. LMWOA (low molecular weight organic acid) exudation by salt marsh plants: Natural variation and response to $\mathrm{Cu}$ contamination Estuarine, Coastal and Shelf Science 88, 63-70. maritimus and Scirpus maritimus) as sources of strong complexing ligands Estuarine, Coastal and 

metal dynamics in salt marshes (Tagus Estuary, Portugal) Science of the Total Environment 380, 93-101.

- Pohl, C., Löffler, A., Hennings, U., 2004. A sediment trap flux study for trace metals under seasonal aspects in the stratified Baltic Sea (Gotland Basin; $57^{\circ} 19.20^{\prime} \mathrm{N} ; 20^{\circ} 03.00^{\prime} \mathrm{E}$ ). Marine Chemistry $84,143-160$.

- Plavsic, M., Kwokal, Z., Strmecki, S., Peharec, Z., Omanovic, D., Branica, M. Determination of the copper complexing ligands in the Krka rivers estuary. Fresenius Environmental Bulletin 18(3), 327-334.

573 - Quevauviller, P., Rauret, G., Rubio, R., Lopez-Sanchez, J.F., Ure, A., Bacon, J., Muntau, H., 1997. 574 Certified reference materials for the quality control of EDTA- and acetic acid-extractable contents 575 of trace elements in sewage sludge amended soils (CRMs 483 and 484). Fresenius Journal of Analytical Chemistry 357, 611-618.

577 - Ruzic, I., 1982. Theoretical aspects of the direct titration of natural waters and its information yield for trace metal speciation. Analytica Chimica Acta 140, 99-113.

579 - Santos-Echeandía, J., Laglera, L.M., Prego, R., van den Berg, C.M.G., 2008. Copper speciation in estuarine waters by forward and reverse titrations. Marine Chemistry108 (3-4), 148-158.

- Santos-Echeandia, J., Laglera, L.M., Prego, R., van den Berg, C.M.G., 2008. Dissolved copper speciation behaviour during estuarine mixing in the San Simon Inlet (wet season, Galicia). Influence of particulate matter. Estuarine Coastal and Shelf Science76, 447-453. Galician Ria (NW Iberian Peninsula): implications for benthic fluxes of dissolved trace elements (Co, $\mathrm{Cu}, \mathrm{Ni}, \mathrm{Pb}, \mathrm{V}, \mathrm{Zn}$ ). Marine Chemistry 117, 77-87. estuary, Portugal) Marine Environmental Research 70, 358-367. 

metal baselines in coastal waters at a regional scale: The case of the Portuguese coast (SW Europe). Marine Environmental Research, in press.

- Shank, G.C., Skrabal, S.A., Whitehead, R.F., Kieber, R.J., 2004a. Strong copper complexation in an organic-rich estuary: the importance of allochthonous dissolved organic matter. Marine Chemistry 88, 21-39.

- Shank, G.C., Skrabal, S.A., Whitehead, R.F., Kieber, R.J., 2004b. Fluxes of strong Cu-complexing ligands from sediments of an organic-rich estuary. Estuarine Coastal and Shelf Science 60 (2): 349-358.

- Skrabal, S.A., Donat, J.R., Burdige, D.J., 1997. Fluxes of copper-complexing ligands from estuarine sediments. Limnology and Oceanography 42, 992-996.

- Skrabal, S.A., Donat, J.R., Burdige, D.J., 2000. Pore water distributions of dissolved copper and coppercomplexing ligands in estuarine and coastal marine sediments. Geochimica et Cosmochimica Acta 64, 1843-1857. on the roots of salt marsh plants: Mechanism and rate of formation. Limnology and Oceanography 43, 245-252.

606

- Turoczy, N.J., Sherwood, J.E., 1997. Modification of the van den Berg/ Ruzic method for the investigation of complexation parameters of natural waters. Analytica Chimica Acta $354(1-3)$,

- Van den Berg, C.M.G., 1982. Determination of copper complexation with natural organic ligands in seawater by equilibration with $\mathrm{MnO} 2 \mathrm{I}$. Theory. Marine Chemistry 11 (4), 307-322. windows. Analytica Chimica Acta 257 (2), 281-291. 

southeastern United States. Environ. Sci. Technol. 23, 314-320.

617 - Zwolsman, J.J.G., van Eck, G.T.M., 1999. Geochemistry of major elements and trace metals in

Netherlands. Marine Chemistry 66 (1-2), 91-111. 


\section{Figure captions.}

Figure 1. Map of the Tagus estuary with the estuarine sampling stations and the Rosário salt-marsh (a) and schematic illustration of the sampling procedure in the salt-marsh

Figure 2. Dissolved copper and copper complexing ligands distribution during the Tagus estuarine mixing (a) $5 \mu \mathrm{M}$ SA and (b) $10 \mu \mathrm{M}$ SA detection windows. Values presented are the mean of three replicates.

Figure 3. Time course evolution of (a) copper and total ligand concentrations in the non-vegetated area $(S P)$ and in the colonized area $(C P)$ for the $5 \mu \mathrm{M}$ detection window, (b) strong $\left(L_{1}\right)$ and weak $\left(L_{2}\right)$ ligand for the $5 \mu \mathrm{M}$ detection window and (c) ligands (total, strong and weak) for the $10 \mu \mathrm{M}$ detection window in flooding waters. Values presented are the mean of three replicates.

\section{Supplementary material}

Figure S1. Suspended particulate matter levels (a), particulate copper and aluminium concentrations (b), and labile copper concentrations (c) in the Tagus estuarine waters. Values presented are the mean of three replicates.

Figure S2. Ligand to copper ratios for the total ligand $(L)$ and strong ligand $\left(L_{1}\right)$ along the salinity gradient of the Tagus estuary.

Figure S3. (a) Low to high detection window ratios for the strong $\left(\mathrm{L}_{1}\right)$ and weak $\left(\mathrm{L}_{2}\right)$ ligand in the Tagus estuarine waters. (b) High to low detection window ratios for the strong $\left(L_{1}\right)$ and weak $\left(L_{2}\right)$ conditional stability constants. 


\section{Figure}

Click here to download high resolution image
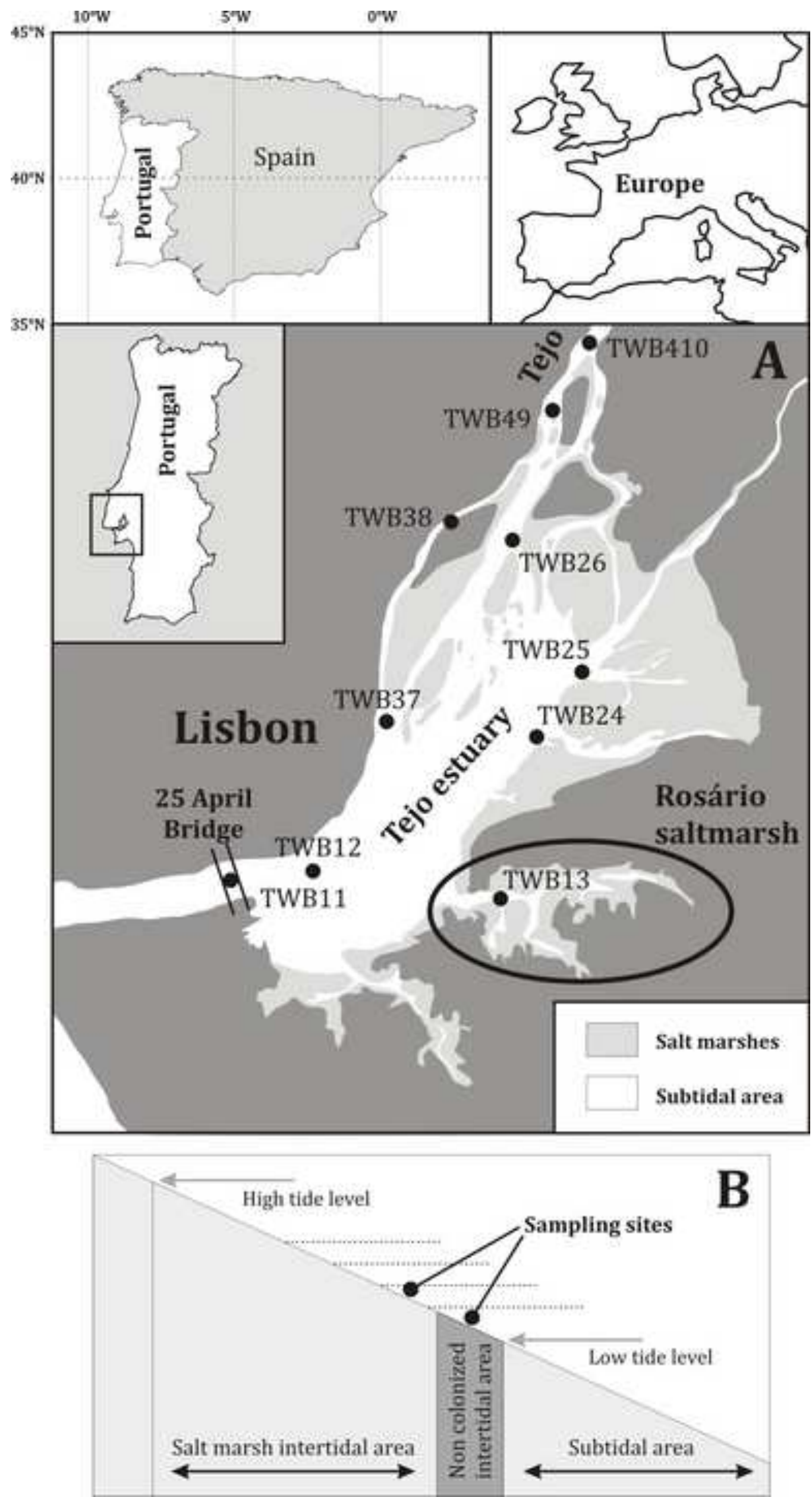
Figure 2.
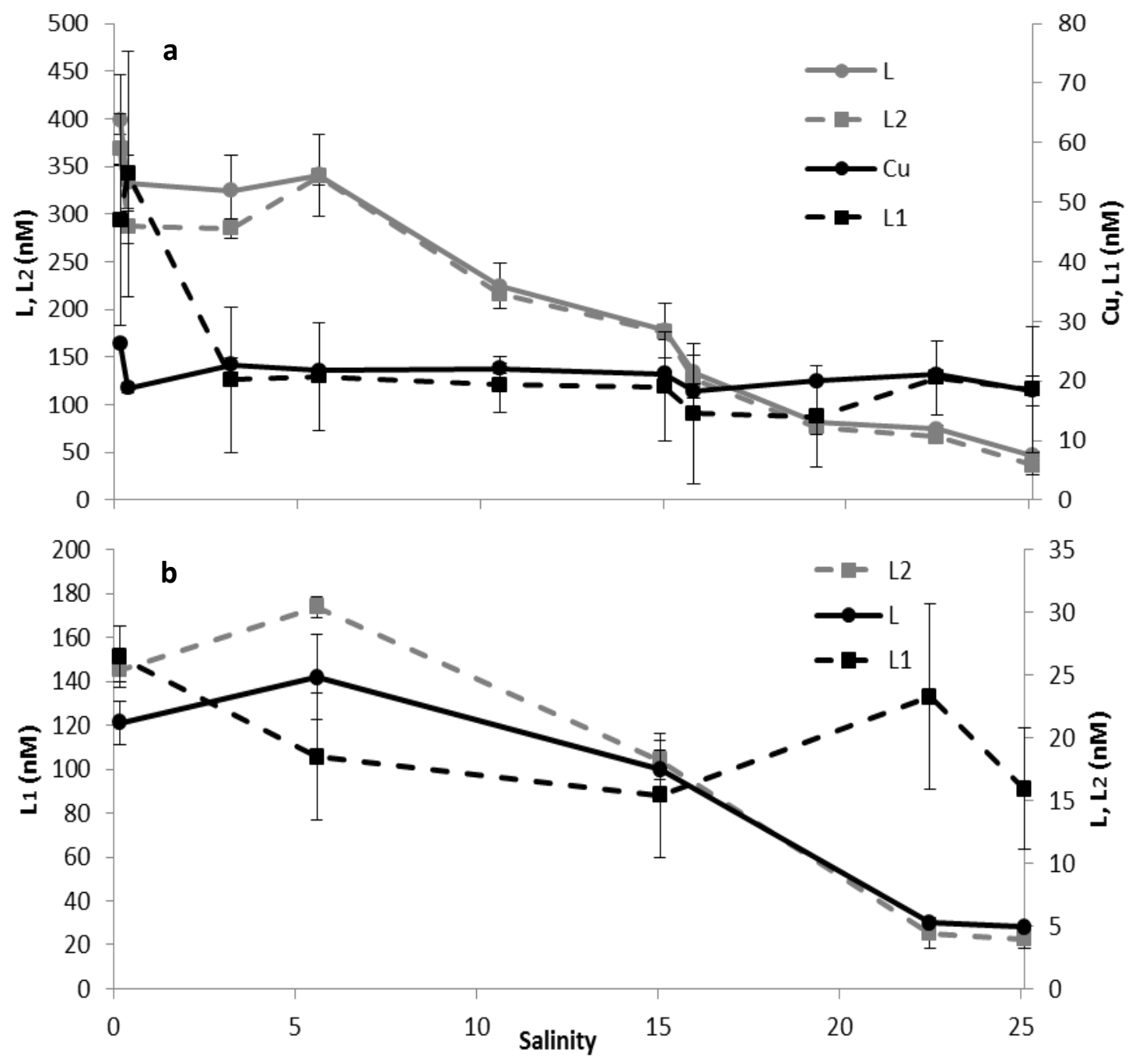

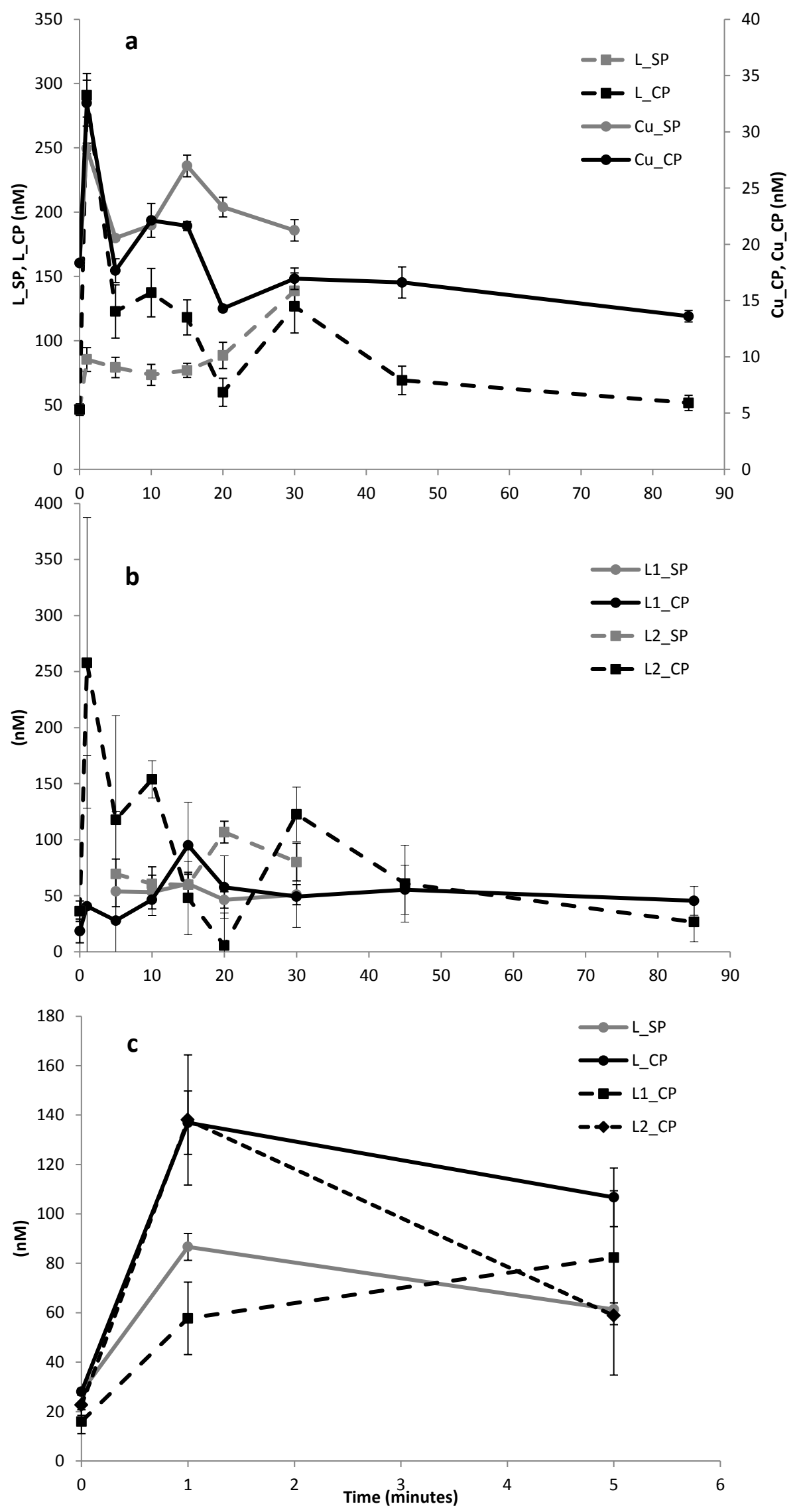

Figure 3. 
Table 1. Dissolved ligand concentrations (nM) and conditional stability constants at two different detection windows (5 $\mu \mathrm{M}$ SA and $10 \mu \mathrm{M}$ SA) in the Tagus estuarine waters. * sample 11, non linear fitting underestimated $S, S^{\mathrm{INT}}$ was used. Values underlined were obtained from an iterative linear fitting and used to obtain the rest of the parameters by nonlinear fitting. Values presented are the mean of three replicates.

\begin{tabular}{|c|c|c|c|c|c|c|c|c|c|c|c|c|c|}
\hline \multirow[b]{2}{*}{ Station } & \multirow[b]{2}{*}{ Salinity } & \multicolumn{6}{|c|}{$5 \mu \mathrm{M} \mathrm{SA}$} & \multicolumn{6}{|c|}{$10 \mu \mathrm{M} \mathrm{SA}$} \\
\hline & & $\mathrm{L}(\mathrm{nM})$ & Log $K^{\prime}$ & $\mathrm{L}_{1}(\mathrm{nM})$ & Log $K_{1}^{\prime}$ & $\mathrm{L}_{2}(\mathrm{nM})$ & Log $K_{2}^{\prime}$ & $\mathrm{L}(\mathrm{nM})$ & Log $K^{\prime}$ & $\mathrm{L}_{1}(\mathrm{nM})$ & Log $K_{1}^{\prime}$ & $\mathrm{L}_{2}(\mathrm{nM})$ & Log $K_{2}^{\prime}$ \\
\hline TWB 410 & 0.2 & $399 \pm 48$ & $13.15 \pm 0.11$ & $47.0 \pm 17.8$ & $15.09 \pm 0.09$ & $368 \pm 16$ & $12.96 \pm 0.09$ & $121 \pm 10$ & $14.52 \pm 0.11$ & $26.4 \pm 2.5$ & $16.84 \pm 0.50$ & $145 \pm 6$ & $13.87 \pm 0.05$ \\
\hline TWB 49 & 0.4 & $333 \pm 30$ & $13.26 \pm 0.09$ & $54.8 \pm 20.6$ & $15.10 \pm 0.35$ & $287 \pm 19$ & $13.13 \pm 0.10$ & & & & & & \\
\hline TWB 38 & 3.2 & $325 \pm 37$ & $12.45 \pm 0.07$ & $20.2 \pm 12.3$ & $15.75 \pm 1.53$ & $285 \pm 11$ & $12.38 \pm 0.08$ & & & & & & \\
\hline TWB 26 & 5.6 & $341 \pm 43$ & $12.21 \pm 0.06$ & $20.7 \pm 9.0$ & $14.16 \pm 0.41$ & $339 \pm 9$ & $12.08 \pm 0.06$ & $142 \pm 19$ & $13.13 \pm 0.11$ & $18.5 \pm 5.1$ & $15.02 \pm 0.44$ & $174 \pm 5$ & $12.76 \pm 0.05$ \\
\hline TWB 37 & 10.5 & $225 \pm 24$ & $12.25 \pm 0.08$ & $19.4 \pm 4.7$ & $14.79 \pm 0.54$ & $217 \pm 5$ & $12.09 \pm 0.04$ & & & & & & \\
\hline TWB 25 & 15.1 & $178 \pm 29$ & $12.26 \pm 0.11$ & $19.0 \pm 9.2$ & $14.10 \pm 0.46$ & $176 \pm 8$ & $12.06 \pm 0.10$ & $100 \pm 9$ & $13.11 \pm 0.09$ & $15.4 \pm 5.0$ & $14.71 \pm 0.37$ & $104 \pm 9$ & $12.76 \pm 0.10$ \\
\hline TWB 24 & 15.8 & $134 \pm 18$ & $12.27 \pm 0.12$ & $14.5 \pm 11.8$ & $14.14 \pm 0.71$ & $126 \pm 10$ & $12.08 \pm 0.16$ & & & & & & \\
\hline TWB 12 & 19.2 & $82.4 \pm 5.5$ & $12.75 \pm 0.08$ & $14.0 \pm 8.5$ & $14.86 \pm 1.14$ & $76.9 \pm 7.5$ & $12.37 \pm 0.16$ & & & & & & \\
\hline TWB 11* & 22.5 & $74.6 \pm 4.0$ & $12.93 \pm 0.11$ & $20.6 \pm 6.2$ & $14.37 \pm 0.42$ & $66.5 \pm 5.4$ & $12.29 \pm 0.19$ & $30.0 \pm 2.2$ & $14.15 \pm 0.19$ & $23.3 \pm 7.4$ & $14.59 \pm 0.45$ & $25.1 \pm 6.5$ & $12.50 \pm 0.34$ \\
\hline TWB 13 & 25.1 & $46.5 \pm 4.3$ & $13.11 \pm 0.13$ & $18.6 \pm 10.6$ & $14.14 \pm 0.43$ & $36.2 \pm 9.2$ & $12.42 \pm 0.59$ & $28.0 \pm 1.3$ & $13.76 \pm 0.07$ & $15.9 \pm 4.9$ & $14.56 \pm 0.41$ & $22.6 \pm 4.2$ & $12.76 \pm 0.27$ \\
\hline
\end{tabular}


Table 2. Dissolved ligand concentrations and conditional stability constants at two different detection windows ( $5 \mu \mathrm{M}$ SA and $10 \mu \mathrm{M}$ SA) in the flooding waters for the non-vegetated and vegetated areas of the Rosário salt-marsh. Values presented are the mean of three replicates.

\begin{tabular}{|c|c|c|c|c|c|c|c|c|c|c|c|c|}
\hline \multirow[b]{3}{*}{$\begin{array}{c}\text { Time } \\
\text { (minutes) }\end{array}$} & \multicolumn{6}{|c|}{ Non-vegetated area } & \multicolumn{6}{|c|}{ Vegetated area } \\
\hline & \multicolumn{12}{|c|}{$5 \mu M S A$} \\
\hline & $L(n M)$ & $\log K^{\prime}$ & $\mathrm{L}_{1}(\mathrm{nM})$ & $\log K_{1}^{\prime}$ & $\mathrm{L}_{2}(\mathrm{nM})$ & $\log \mathrm{K}_{2}^{\prime}$ & $L(n M)$ & $\log K^{\prime}$ & $\mathrm{L}_{1}(\mathrm{nM})$ & $\log K_{1}^{\prime}$ & $\mathrm{L}_{2}(\mathrm{nM})$ & $\log \mathrm{K}_{2}^{\prime}$ \\
\hline 0 & $46.5 \pm 4.4$ & $13.11 \pm 0.10$ & $18.6 \pm 10.6$ & $14.00 \pm 0.43$ & $36.2 \pm 9.2$ & $12.42 \pm 0.59$ & $46.5 \pm 4.4$ & $13.11 \pm 0.10$ & $18.6 \pm 11$ & $14.00 \pm 0.43$ & $36.2 \pm 9.2$ & $12.42 \pm 0.59$ \\
\hline 1 & $85.4 \pm 9.3$ & $14.04 \pm 0.26$ & & & & & $291 \pm 17$ & $13.11 \pm 0.09$ & $40.5 \pm 134$ & $14.08 \pm 0.81$ & $258 \pm 130$ & $12.91 \pm 0.27$ \\
\hline 5 & $79.2 \pm 7.9$ & $13.73 \pm 0.19$ & $53.8 \pm 13.6$ & $14.17 \pm 0.52$ & $69.3 \pm 13.3$ & $12.18 \pm 0.29$ & $123 \pm 21$ & $13.55 \pm 0.63$ & $27.7 \pm 97$ & $14.83 \pm 1.13$ & $118 \pm 93$ & $13.05 \pm 0.50$ \\
\hline 10 & $73.5 \pm 8.1$ & $13.94 \pm 0.25$ & $53.2 \pm 15.0$ & $14.32 \pm 0.79$ & $60.6 \pm 15.2$ & $12.22 \pm 0.35$ & $137 \pm 19$ & $13.22 \pm 0.26$ & $46.5 \pm 14$ & $14.71 \pm 0.36$ & $154 \pm 17$ & $12.27 \pm 0.18$ \\
\hline 15 & $77.0 \pm 5.5$ & $13.84 \pm 0.13$ & $60.6 \pm 8.5$ & $14.12 \pm 0.24$ & $59.7 \pm 11.2$ & $12.01 \pm 0.26$ & $118 \pm 14$ & $13.40 \pm 0.19$ & $95.0 \pm 38$ & $13.61 \pm 0.25$ & $47.9 \pm 33$ & $11.96 \pm 0.62$ \\
\hline 20 & $88.6 \pm 10.3$ & $13.77 \pm 0.26$ & $46.3 \pm 7.4$ & $14.79 \pm 0.54$ & $107 \pm 9.8$ & $12.26 \pm 0.16$ & $59.9 \pm 11$ & $13.88 \pm 0.63$ & $57.6 \pm 28$ & $13.92 \pm 0.36$ & $5.5 \pm 29$ & $11.96 \pm 1.38$ \\
\hline 30 & $139 \pm 14$ & $13.91 \pm 0.23$ & $50.9 \pm 8.9$ & $14.31 \pm 0.41$ & $70.1 \pm 16.8$ & $11.95 \pm 0.25$ & $127 \pm 21$ & $13.22 \pm 5.13$ & $49.2 \pm 28$ & $14.14 \pm 0.39$ & $123 \pm 24$ & $12.30 \pm 0.31$ \\
\hline 45 & & & & & & & $69.2 \pm 11$ & $13.76 \pm 5.15$ & $55.4 \pm 22$ & $14.00 \pm 0.33$ & $60.8 \pm 34$ & $11.87 \pm 0.50$ \\
\hline \multirow[t]{2}{*}{85} & & & & & & & $51.7 \pm 5.9$ & $13.89 \pm 5.07$ & $45.5 \pm 13$ & $14.03 \pm 0.25$ & $26.5 \pm 18$ & $11.99 \pm 0.59$ \\
\hline & \multicolumn{12}{|c|}{$10 \mu \mathrm{M} S A$} \\
\hline 0 & $28.0 \pm 1.3$ & $13.76 \pm 0.07$ & $15.9 \pm 4.9$ & $14.56 \pm 0.41$ & $22.6 \pm 4.2$ & $12.76 \pm 0.27$ & $28.0 \pm 1.3$ & $13.76 \pm 0.07$ & $15.9 \pm 4.9$ & $14.56 \pm 0.41$ & $22.6 \pm 4.2$ & $12.76 \pm 0.27$ \\
\hline 1 & $86.7 \pm 5.4$ & $14.48 \pm 0.10$ & & & & & $137 \pm 13$ & $14.47 \pm 0.17$ & $57.7 \pm 15$ & $15.69 \pm 0.39$ & $138 \pm 26$ & $13.44 \pm 0.21$ \\
\hline 5 & $61.4 \pm 2.6$ & $14.39 \pm 0.06$ & & & & & $107 \pm 12$ & $14.32 \pm 0.20$ & $82.3 \pm 27$ & $14.63 \pm 0.26$ & $58.8 \pm 24$ & $12.84 \pm 0.49$ \\
\hline
\end{tabular}


Table 3. Dissolved copper and ligand concentrations and conditional stability constants at two different detection windows ( $5 \mu \mathrm{M}$ SA and $10 \mu \mathrm{M}$ SA) in the porewaters of the Rosário salt-marsh for the non-vegetated and vegetated areas. Values presented are the mean of three replicates.

\begin{tabular}{|c|c|c|c|c|c|c|c|c|c|c|c|c|c|c|}
\hline \multicolumn{15}{|c|}{ ROSARIO SALT-MARSH (5 $\mu \mathrm{M}$ SA) } \\
\hline & \multicolumn{7}{|c|}{ Non-vegetated area } & \multicolumn{7}{|c|}{ Vegetated area } \\
\hline $\begin{array}{l}\text { Depth } \\
(\mathrm{cm})\end{array}$ & $\begin{array}{c}\mathrm{Cu} \\
(\mathrm{nM})\end{array}$ & $\begin{array}{c}\mathrm{L} \\
(\mathrm{nM})\end{array}$ & Log $K^{\prime}$ & $\begin{array}{c}\mathrm{L}_{1} \\
(\mathrm{nM})\end{array}$ & $\log \mathrm{K}_{1}^{\prime}$ & $\mathrm{L}_{2}$ & $\log K_{2}^{\prime}$ & $\begin{array}{c}\mathrm{Cu} \\
(\mathrm{nM})\end{array}$ & $\begin{array}{c}\mathrm{L} \\
(\mathrm{nM})\end{array}$ & Log K' & $\begin{array}{c}\mathrm{L}_{1} \\
(\mathrm{nM})\end{array}$ & $\log \mathrm{K}_{1}^{\prime}$ & $\mathrm{L}_{2}$ & $\log \mathrm{K}_{2}^{\prime}$ \\
\hline 2 & $53.9 \pm 5.4$ & $245 \pm 32$ & $13.58 \pm 0.28$ & $184 \pm 24$ & $13.70 \pm 1.03$ & $70.1 \pm 24$ & $13.09 \pm 1.42$ & $142 \pm 8$ & $831 \pm 80$ & $13.55 \pm 0.19$ & $203 \pm 187$ & $15.17 \pm 0.82$ & $666 \pm 176$ & $13.09 \pm 0.27$ \\
\hline 6 & $45.3 \pm 1.0$ & $321 \pm 34$ & $13.24 \pm 0.17$ & $77.2 \pm 43$ & $14.77 \pm 0.58$ & $287 \pm 39$ & $12.68 \pm 0.21$ & $70.7 \pm 2.0$ & $767 \pm 36$ & $12.88 \pm 0.07$ & $115 \pm 61$ & $14.66 \pm 0.44$ & $699 \pm 57$ & $12.82 \pm 0.10$ \\
\hline \multicolumn{15}{|c|}{ ROSARIO SALT-MARSH $(10 \mu \mathrm{M}$ SA) } \\
\hline & \multicolumn{7}{|c|}{ Non-vegetated área } & \multicolumn{7}{|c|}{ Vegetated área } \\
\hline 2 & $53.9 \pm 5.4$ & $230 \pm 18$ & $14.28 \pm 0.10$ & $66.8 \pm 94$ & $15.25 \pm 0.71$ & $182 \pm 89$ & $13.85 \pm 0.29$ & $142 \pm 8$ & $419 \pm 13$ & $13.95 \pm 0.14$ & $148 \pm 55$ & $17.56 \pm 2.44$ & $846 \pm 65$ & $13.51 \pm 0.22$ \\
\hline
\end{tabular}


Table 4. Estimated tidal induced transport of dissolved copper and complexing ligands in Rosário sediments for the non-vegetated and colonized areas.

\begin{tabular}{lccc}
\hline & \multicolumn{2}{c}{ Tidal induced transport $\left(\mu \mathrm{mol} \mathrm{m}^{-2} \mathrm{~d}^{-1}\right)$} \\
\hline $5 \mu \mathrm{M} \mathrm{SA}$ & & Non-vegetated & Colonized \\
& $\mathrm{Cu}$ & 1.23 & \\
& $\mathrm{~L}$ & 3.25 & 2.43 \\
& $\mathrm{~L}_{1}$ & 2.16 & 48.2 \\
& $\mathrm{~L}_{2}$ & 2.31 & 11.5 \\
$10 \mu \mathrm{M}$ SA & & & 64.7 \\
& $\mathrm{~L}$ & 4.25 & \\
& $\mathrm{~L}_{1}$ & - & 6.87 \\
& $\mathrm{~L}_{2}$ & - & 3.80 \\
\end{tabular}


Electronic Supplementary Material (online publication only)
Click here to download Electronic Supplementary Material (c

Click here to download Electronic Supplementary Material (online publication only): Figure_S1.docx 
Electronic Supplementary Material (online publication only)
Click here to download Electronic Supplementary Material (c

Click here to download Electronic Supplementary Material (online publication only): Figure_S2.docx 
Electronic Supplementary Material (online publication only)
Click here to download Electronic Supplementary Material (c

Click here to download Electronic Supplementary Material (online publication only): Figure_S3.docx 